(a) (1) https://creativecommons.org/licenses/by/4.0/

ARTIGO

\title{
PRODUÇÃO DE CONHECIMENTO SOBRE ENSINO MÉDIO INTEGRADO À EDUCAÇÃO PROFISSIONAL: UM PANORAMA CIENCIOMÉTRICO
}

\author{
EVELIZE DORNELES MINUZZI ${ }^{1}$ \\ ORCID: https://orcid.org/0000-0002-5738-9438 \\ RENATO XAVIER COUTINHO ${ }^{2}$ \\ ORCID: https://orcid.org/0000-0001-6602-2120
}

\begin{abstract}
RESUMO: O Ensino Médio Integrado se constitui como uma política educacional voltada para a integração do ensino médio com a educação profissional, conforme explicita o Decreto $n^{\circ} 5.154 / 04$, sendo responsabilidade prioritária da Rede Federal de Educação Profissional, Científica e Tecnológica, sobretudo, dos Institutos Federais de Educação, Ciência e Tecnologia (IFs), criados a partir da Lei n ${ }^{\circ}$ 11.892/2008. No entanto, tem-se percebido que o Ensino Médio Integrado ainda é um desafio que está se consolidando tanto em aspectos teóricos quanto práticos. Isso tem gerado algumas reformulações nas políticas educacionais e produziu um aumento nas pesquisas científicas sobre Ensino Médio Integrado. Nesse sentido, este estudo tem como objetivo analisar a produção de conhecimento sobre o Ensino Médio Integrado nos IFs, no período compreendido entre janeiro de 2008 a março de 2019. Para tanto, elegeu-se a Biblioteca Digital Brasileira de Teses e Dissertações para buscar os dados, tomando como base a cienciometria para analisá-los. Constituem o corpus de análise 159 produções acadêmicas, compostas por dissertações e teses. Conclui-se que, a produção de conhecimento sobre Ensino Médio Integrado, dos IFs, centra-se na pesquisa básica e empírica, com abordagem qualitativa, e sua principal temática recorre às experiências didático-pedagógicas disciplinares.
\end{abstract}

Palavras-chave: Ensino Médio Integrado, Cienciometria, Institutos Federais de Educação, Ciência e Tecnologia.

\section{PRODUCTION OF KNOWLEDGE ON INTEGRATED HIGH SCHOOL PROFESSIONAL EDUCATION: A SCIENCIOMETRIC PANORAMA}

\begin{abstract}
Integrated High School is an educational policy aimed to integrating high school with vocational education, as explicitly stated in Decree No. 5,154/04, being a priority responsibility of the Federal Network of Professional, Scientific and Technological Education, especially the Federal Institutes of Education, Science and Technology (IFs), created from Law No. 11.892/2008. However, it has been realized that Integrated High School is still a challenge, because it is consolidating both theoretical and practically. This has led to some reformulations in educational policies and a rise of scientific researches on Integrated High School. In this sense, this study aims to analyze the production of knowledge about
\end{abstract}

\footnotetext{
1 Instituto Federal Farroupilha, Campus São Vicente do Sul. São Vicente do Sul, RS, Brasil. <evelize.minuzzi@iffarroupilha.edu.br>

2 Instituto Federal Farroupilha, Campus São Vicente do Sul. São Vicente do Sul, RS, Brasil. $<$ renato.coutinho@iffarroupilha.edu.br >
} 
the Integrated High School in Federal Institutes of Education, in the period from January 2008 to March 2019. The Brazilian Digital Library of Theses and Dissertations was chosen as database, to a scientometric analysis. The corpus constituted 159 academic productions, composed by dissertations and theses. In conclusion, the production of knowledge about Integrated High School in Brazilian Federal Institutes of Education focuses on basic and empirical research, with qualitative approach and its main theme is the didactic-pedagogical disciplinary experiences.

Keywords: Integrated High School, Scientometric, Federal Institutes of Education, Science and Technology.

\section{PRODUCCIÓN DE CONOCIMIENTOS SOBRE LA EDUCACIÓN PROFESIONAL INTEGRADA EN LA ESCUELA SECUNDARIA: UNA VISIÓN GENERAL CIENCIOMÉTRICA}

RESÚMEN: Enseñanza secundaria integrada es una política educativa destinada a integrar la escuela secundaria con la educación vocacional, como se establece explícitamente en el Decreto No. 5,154/04, y es la responsabilidad principal de la Rede Federal de Educación Vocacional, Científica y Tecnológica, especialmente los Institutos Federales de Educación, Ciencia y Tecnología (IFs), creadas a partir de la Ley $\mathrm{N}^{\circ} 11.892 / 2008$. Sin embargo, se ha dado cuenta de que la Escuela secundaria integrada sigue siendo un desafío, que está en proceso de consolidación, tanto ne los aspectos teóricos como prácticos. Esto ha llevado a algunas reformulaciones en las políticas educativas y en un aumento en la investigación científica sobre la escuela secundaria integrada. En este sentido, este estudio tiene como objetivo analizar la producción de conocimiento sobre la escuela secundaria integrada en los IFs, de enero de 2008 a marzo de 2019. Para este fin, se eligió la Biblioteca Digital Brasileña de Tesis y Disertaciones para buscar los datos y la cienciometría para analizar estos. El corpus de análisis constituyó 159 producciones académicas, compuestas de disertaciones y tesis. Se concluye que la producción de conocimiento sobre la Escuela secundaria integrada de las IFs se centra en la investigación básica y empírica, con enfoque cualitativo y su tema principal explora las experiencias disciplinarias didáctico-pedagógicas.

Palabras clave: Escuela secundaria integrada, Cienciometria, Institutos Federales de Educación, Ciencia y Tecnología. 


\section{INTRODUÇÃO}

O Ensino Médio Integrado se reverbera como uma política educacional, por meio da articulação da Educação Profissional Técnica de Nível Médio e do Ensino Médio, sendo "oferecido somente a quem já tenha concluído o ensino fundamental, de modo a conduzir o aluno à habilitação profissional técnica de nível médio, na mesma instituição de ensino, contando com uma matrícula única para cada aluno", conforme explícita a redação do Decreto $n^{\circ} 5.154 / 04$, contrapondo o Decreto 2.208/97 que assegurava a separação entre a Educação Profissional e a Educação Básica.

Tal projeto se configura como uma proposta de enfrentamento a dualidade estrutural da educação, que confirmou ao longo da história a divisão social e técnica do trabalho, acentuada pelo sistema de produção capitalista, com uma formação mais instrumental voltada aos trabalhadores, paralela aquela educação propedêutica ofertada à elite, destinada a formação de dirigentes. Pois, o Ensino Médio Integrado pretende articular o fazer e pensar, num único processo formativo, sob a perspectiva da humanização e emancipação humana, perpassando pelas categorias da omnilateralidade, politecnia e formação humana integral, fundamentadas em Marx e Engels e Gramsci, com um currículo que articula o trabalho, a tecnologia, a ciência e a cultura.

Atualmente, o Ensino Médio Integrado é responsabilidade prioritária da Rede Federal de Educação Profissional, Científica e Tecnológica, instituída pela Lei no ${ }^{\circ} 11.892 / 2008$, junto com a criação dos Institutos Federais de Educação, Ciência e Tecnologia (IFs), os quais tem como um dos seus objetivos "ministrar educação profissional técnica de nível médio, prioritariamente na forma de cursos integrados, para os concluintes do ensino fundamental e para o público da educação de jovens e adultos". Dessa forma, os IFs devem garantir o mínimo de 50\% das suas vagas para a Educação Profissional Técnica de Nível Médio, prioritariamente, na forma integrada. Isso fez com que no ano de 2017, cerca de 509 IFs ofertassem o Ensino Médio Integrado, com 223.869 mil matriculados, os quais estão presentes em mais de 10\% dos municípios brasileiros, de acordo com a Plataforma Nilo Peçanha.

Em decorrência dessa materialidade institucional e territorial dada pelos IFs, o Ensino Médio Integrado passou a ser também um tema emergente de análise e discussão no cenário educacional, tanto em termos de publicações e reformulações de políticas públicas, quanto de objeto de estudo de pesquisas científicas, sobretudo, de dissertações e teses. Essas têm sido legitimadas pela crescente realização de eventos científicos, constituição de revistas e programas de pós-graduação (stricto sensu), voltados à Educação Profissional e Tecnológica. Nesse sentido, Coutinho et al. (2012) destacam que o relacionamento colaborativo entre a universidade e a escola pode qualificar e adequar as pesquisas à realidade escolar, como também favorecer uma melhoria da qualidade do ensino, na medida em que, há um contexto de compartilhamento do conhecimento científico e das experiências pedagógicas.

Por outro lado, não se tem uma sistematização acerca da quantidade da produção de conhecimento sobre Ensino Médio Integrado, concomitante, aos 10 anos de IFs. Essa deficiência, muitas vezes, não permite localizar e subsidiar a compreensão de suas tendências, enquanto objeto de pesquisa, e nem apontar suas possibilidades e limites como práxis, visto que os estudos encontrados referem-se apenas ao mapeamento das produções, usando o estado de conhecimento como abordagem (Vieira; Vieira, 2016; Drago, 2017; Cavalcanti; Neta, 2015), e não sob a interface cienciométrica, que "avalia a produção científica, mediante indicadores numéricos e uso de técnicas e análises estatísticas amplamente discutidos e validados", conforme define Razera (2016, p. 558).

Diante da lacuna de estudos cienciométricos sobre o Ensino Médio Integrado, essa pesquisa se justifica, no sentido de buscar as produções acadêmicas que demonstrem os seus percursos retrospectivos e rumos atualizados, lançando luz sobre iniciativas futuras no que tange as políticas educacionais e a área de pesquisa da Educação Profissional Técnica de Nível Médio, especialmente, do Ensino Médio Integrado, no Brasil. Por isso, o fato de quantificar e avaliar a produção acadêmica referente ao Ensino Médio Integrado (o que/quanto/onde/como/por quê/para quem está sendo produzido?), delineada em um único manuscrito e sob o viés da cienciometria, permitirá visualizar suas especificações na totalidade do fenômeno, impulsionar como área de pesquisa e pontuar os impactos na sua conceituação e materialização, tanto na base legal quanto teórica, perpetuando a valorização da Educação Profissional pública, gratuita e de qualidade. 
De tal modo, o presente artigo buscará preencher essa carência ao analisar as produções acadêmicas que tratam do Ensino Médio Integrado, ofertado pelos IFs, por meio da cienciometria, no período de janeiro de 2008 a março de 2019, a partir da Biblioteca Digital Brasileira de Teses e Dissertações. Para tanto, torna-se necessário efetuar um mapeamento acerca do ano das publicações, da distribuição geográfica das instituições de ensino e áreas de concentração dos programas de pósgraduação stricto sensu, dos assuntos abordados, da abordagem do problema, dos instrumentos aplicados na coleta de dados, do tipo de pesquisa e lócus/participantes apresentados pelas dissertações e teses.

Considerando que o tema da Educação Profissional Técnica de Nível Médio tem sido recorrente no debate educacional, esse estudo cienciométrico pretende ajudar a traçar um panorama quantitativo do que tem sido desenvolvido sobre o Ensino Médio Integrado, dos IFs, nos últimos 10 anos, em consonância com a discussão acerca da literatura, além de servir como apoio para futuras pesquisas, em especial, as aplicadas e de abordagem quantitativa; as que investigarão a prática interdisciplinar e a integração curricular; e as que avaliarão os impactos e a eficiência da qualidade do Ensino Médio Integrado nos índices nacionais e internacionais. Desse modo, busca-se avançar e legitimar o projeto de formação integrada, sobretudo, em contextos emergentes às políticas e gestão da Educação Básica.

\section{ENCAMINHAMENTO METODOLÓGICO}

Fonte Diante do objetivo pretendido, esse estudo caracteriza-se pela abordagem qualiquantitativa e pelo viés descritivo (GIL, 2008). Além disso, trata-se de um estudo documental, uma vez que recorreu diretamente aos registros - teses e dissertações, sem trato analítico, para identificar e extrair, cuidadosamente, as informações de interesse do estudo, as quais serão estruturadas a partir das orientações teórico-metodológicas da cienciometria. Para Spinak (1996), o conceito de cienciometria perpassou por um processo de evolução diante do tempo, inicialmente, limitava-se à medição da informação e, atualmente, faz referências às leis, propriedades e características diversas, que subjazem uma dimensão interdisciplinar da comunicação científica.

Dessa forma, elegeu-se a cienciometria, pois, ao se utilizar um método quantitativo e objetivo, ele permite realizar uma avaliação do estado atual da ciência e auxilia na tomada de decisões e no gerenciamento das pesquisas. Nas palavras de Vanti (2002, p. 155), a cienciometria procura "identificar as tendências e o crescimento do conhecimento em uma área", "medir o grau e padrões de colaboração entre autores" e, também, "medir o crescimento de determinadas áreas e o surgimento de novos temas". Macias-Chapula (1998, p. 134) complementa que "em tudo o que se refere à ciência, os indicadores bibliométricos e cienciométricos tornaram-se essenciais", pois com a identificação das instituições e áreas com maiores potencialidades tem-se um ranqueamento da produção dos centros de pesquisa e dos pesquisadores, o que determina, atualmente, a distribuição dos recursos públicos para a ciência.

Para tal, organizou-se o estudo em duas fases: uma é referente ao levantamento e outra relacionada à análise das produções acadêmicas. Na primeira fase, foi realizada uma pesquisa na plataforma de busca: Biblioteca Brasileira Digital de Teses e Dissertações (BDTD), entre o segundo semestre de 2018 e os três primeiros meses de 2019, havendo algumas variações de resultados no período em questão, em virtude da finalização do ciclo dos programas de pós-graduação stricto sensu, que acontece, majoritariamente, no mês de março. Localizaram-se as produções acadêmicas (dissertações e teses), através de duas buscas: a primeira referente ao cruzamento dos descritores "ensino médio integrado" e "educação profissional", e a segunda relacionada apenas com o descritor "ensino médio integrado". Essa pesquisa permitiu a identificação de 379 produções acadêmicas, dentre essas, 135 referentes à primeira busca e 244 alusivas à segunda.

De forma mais detalhada, o levantamento das produções acadêmicas na BDTD, percorreu os seguintes passos: seleção da opções busca avançada, "ensino médio integrado" e "educação profissional" e, posteriormente, pesquisa por "ensino médio integrado" no campo "título"; exibição de dados no período de "2008-2019" que totalizaram 372 dissertações e teses. 
Para direcionar a constituição do corpus, fez-se uma leitura dos títulos e resumos das 372 produções acadêmicas, a fim de localizar a temática "Ensino Médio Integrado" de forma explícita. Essa leitura indicou que 213 estudos não contemplavam de fato o tema em sua especificidade, em virtude de inúmeras razões, tais como: não tratavam do tema; estavam em duplicidade; não continham como lócus da pesquisa os IFs; não disponibilizavam o documento completo; e abordavam sobre o PROEJA ou sobre a Educação Profissional Tecnológica. Por essas razões, não foram selecionadas.

A partir do recurso metodológico de consulta foi possível conhecer, levantar e acoplar informações que abarcaram as questões geradoras e mediaram a construção do corpus de análise da pesquisa. Desse modo, o corpus da análise cienciométrica foi composto por um total de 159 produções acadêmicas, circunscritas na BDTD, como sintetiza o fluxograma abaixo (Figura 1):

Figura 1. Fluxograma do corpus de análise cienciométrica.

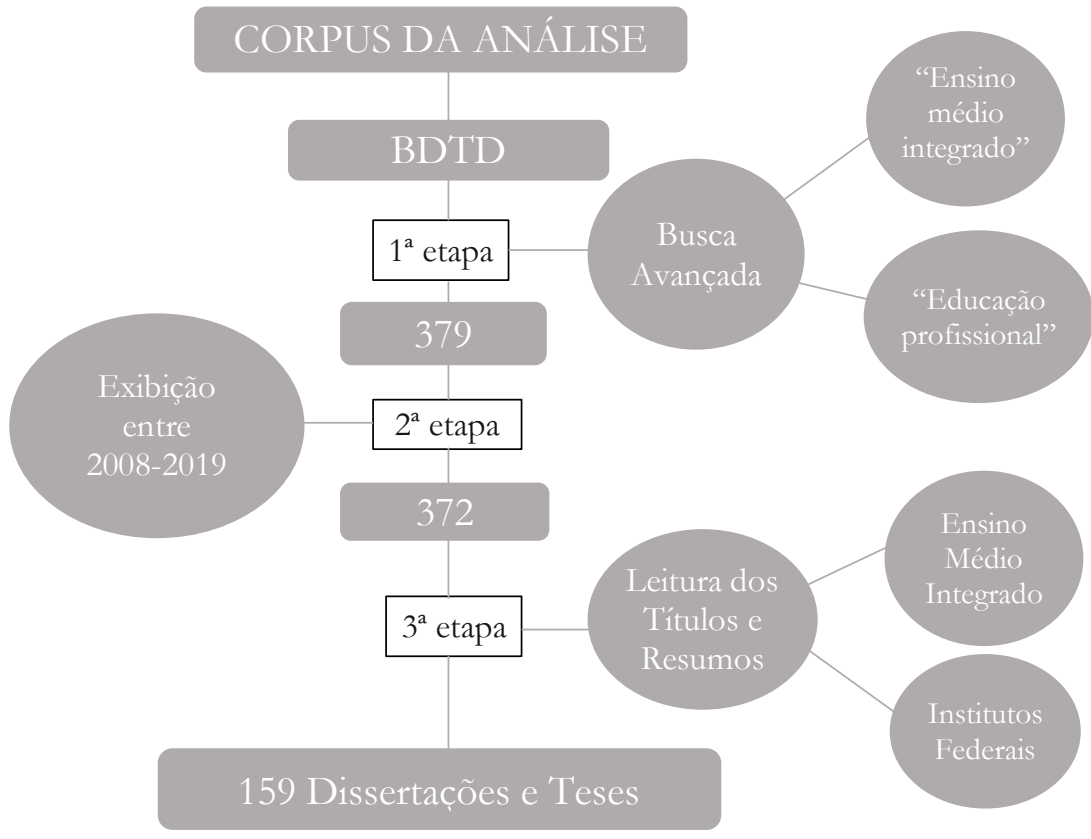

Fonte: os autores.

A partir desse primeiro refinamento, pertinente à constituição do corpus de análise acerca do tema "Ensino Médio Integrado", passou-se a segunda fase, ou seja, a análise das produções acadêmicas, por meio de uma abordagem quantitativa. Buscou, então, investigar os fenômenos, através de medições objetivas e análises quantitativas, conforme define Moreira (2011). E, além disso, utilizouse da matriz analítica, adaptada de Coutinho et al. (2012) para categorizar o conteúdo das produções acadêmicas, o qual foi organizado em uma planilha do Microsoft Excel ${ }^{\mathrm{TM}}$, a partir dos delineamentos observados na Figura 2. 
Figura 2. Matriz analítica para categorizar o conteúdo das produções acadêmicas.

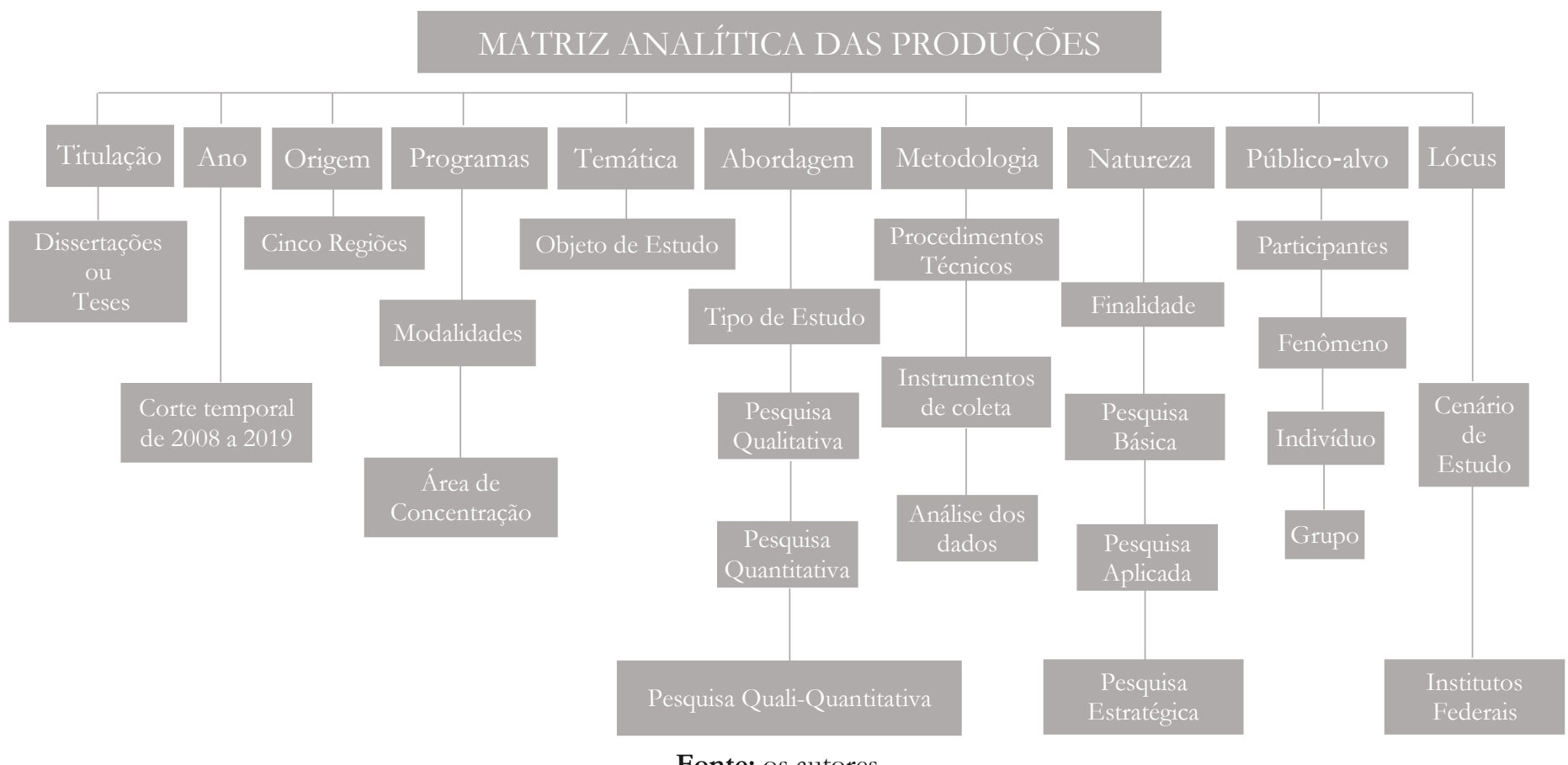

Fonte: os autores.

Assim, os estudos foram categorizados, de acordo com o escopo, operacionalizando a etapa de caracterização descritiva. Reescreveram-se as informações relevantes das 159 produções acadêmicas, a partir da configuração da matriz analítica, em correspondência com Coutinho et al. (2012) e critérios já estabelecidos pela literatura. Tais critérios de classificação em cada categoria serão apresentados a seguir, juntamente com os demais resultados.

\section{RESULTADOS E DISCUSSÃO}

Ao considerar esses nexos tangíveis, optou-se por apresentar a análise cienciométrica em dois momentos: o primeiro que expõe os dados, sob um panorama geral, buscando situar as produções acadêmicas acerca do Ensino Médio Integrado, em termos de: quantitativo de dissertações e teses produzidas, ao longos dos últimos 10 anos; distribuição por ano, no período de janeiro de 2008 a março de 2019; região de origem; programas de pós-graduação vinculados, tanto com relação a sua modalidade (acadêmico ou profissional) e área de concentração. O segundo perpassa pela avaliação das produções acadêmicas, diante das formas clássicas de caracterização de uma pesquisa, quanto: à natureza; ao problema; aos objetivos e aos procedimentos técnicos (SILVA; MENEZES, 2001). Além desses critérios de classificação das pesquisas, utilizou-se o delineamento da temática, do público-alvo e do lócus, correspondendo à matriz analítica de Coutinho et al. (2012), utilizada para complementar a sistematização do perfil dessas produções.

\section{Panorama geral: situando a produção de conhecimento sobre ensino médio integrado}

A apreciação dos 159 resumos permitiu identificar que, do total de estudos analisados, a maioria das produções correspondem a dissertações, cerca de 80,5\% (128), e apenas 19,5\% (31) são teses, como desmonstra a Figura 3: 
Figura 3: Quantitativo de produções acadêmicas.

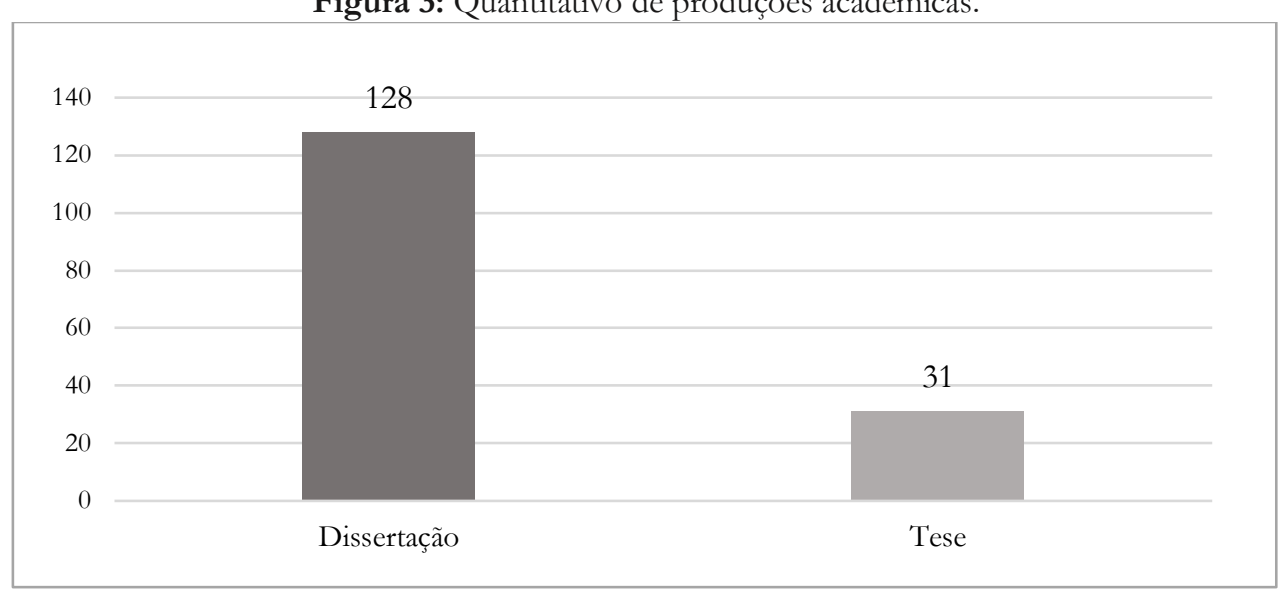

Fonte: os autores.

O número reduzido de teses, se comparado com o total de dissertações, pode ser entendido a partir da lógica de produção do conhecimento científico, a qual é regulada pelo tempo de duração dos cursos, mestrado com 02 anos e doutorado com 04 anos. Essa duração permite exigir, no nível de doutorado, uma produção de conhecimento com aprofundamento teórico maior e cumprimento de alguns requisitos, tais como: originalidade e ineditismo, que demandam tempo para a apropriação e construção de conhecimentos.

Para Saviani (1984, p. 51), a atividade investigadora representa uma "incursão no desconhecido, que só se define por confronto com o conhecido", ou seja, sem o domínio do conhecido não é possível incursionar no desconhecido. Além disso, Abrantes e Martins (2007) destacam a prática social como início do processo de construção do conhecimento e seu resultado, ou seja, isso possibilita estreitar os vínculos entre o sujeito de conhecimento e a realidade, acompanhar o seu movimento e desvelar os determinantes ocultos na aparência. Assim, coloca-se em questão a produção do conhecimento científico como uma das expressões da relação sujeito-objeto que é conduzida pelo tempo.

Diante desse panorama do quantitativo inicial, estabeleceu-se a distribuição das teses e dissertações publicadas por ano, apresentada, na Figura 4, com o propósito de visualizar uma possível popularização da temática.

Figura 4: Distribuição das teses e dissertações por ano.

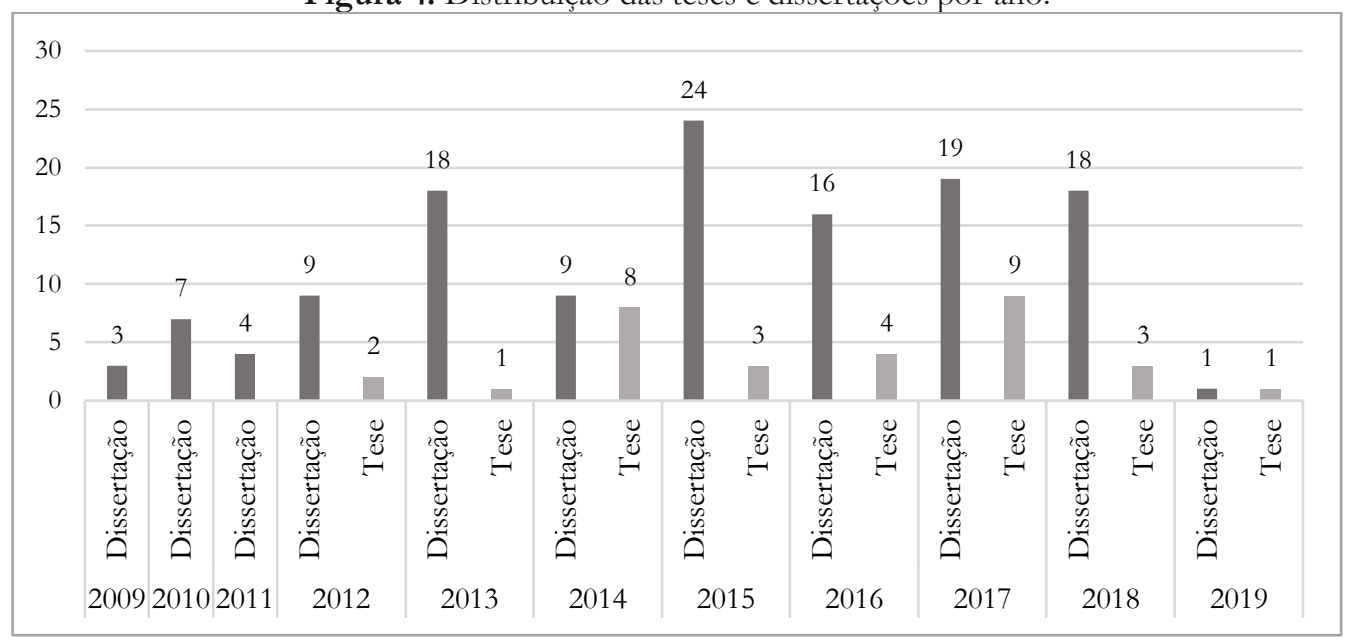

Fonte: os autores.

Considerando o corte temporal analisado, de 2008 a 2019, é preciso ponderar que as primeiras dissertações foram publicadas no ano de 2009 e as primeiras teses no ano de 2012, uma vez que acompanharam a criação dos Institutos Federais de Educação, Ciência e Tecnologia (IFs), por meio da Lei n. 11.892/2008, sancionada por Luiz Inácio da Silva. O reflexo do processo legal de transição de 
Escolas Técnicas Federais para Institutos Federais foi a implementação de uma nova concepção de formação, percebida como uma possibilidade de contradição a dualidade histórica legitimada entre a escola propedêutica e a técnica. Tal contradição pode ser ilustrada pelos títulos das seguintes produções: "A Educação Profissional Técnica de Nível Médio Integrada ao Ensino Médio: implicações das mudanças legais no Governo Lula para o IFG", de Virote (2009), e "Concepção e prática do ensino médio integrado: a percepção dos professores da ETF Palmas-Tocantins”, de Bentes (2009).

Além disso, os resultados apontam que o período mais produtivo de dissertações acerca da temática do Ensino Médio Integrado, está entre os anos de 2015 a 2018 (últimos quatros anos), com um total de 77 dissertações, equivalendo a $60,1 \%$ das publicações do período correspondente. E, no nível do doutorado, os anos de 2014 e 2017 sobressaem-se aos demais, com o número de 17 teses, referindose a $54,8 \%$ das produções do período citado.

Esse aumento significativo das produções acadêmicas, em especial, das dissertações, pode ser justificado pela expansão dos cursos de pós-graduação strito sensu no país, seja na modalidade acadêmica quanto na profissional, impulsionada pelo cenário das políticas externas e internas, da firmação de convênios internacionais e do investimento de apoio (concessão de bolsas), manutenção, qualidade e expansão, dado pela Coordenação de Aperfeiçoamento de Pessoal de Nível Superior (Capes), a partir de 2008.

Sob esse cenário, Lievore, Picinin e Pilatti (2017, p. 216) demonstraram que, no ano de 2014, os programas de pós-graduação atingiram um quantitativo de "232.381 alunos matriculados, em que, 49,73\% eram alunos de mestrado acadêmico, 9,45\% de mestrado profissional e 40,82\% alunos de doutorado", exemplificando o seu crescimento, que foi de $192 \%$.

No entanto, Ferreira (2009, p. 51) chama atenção para a isenção do Estado quanto à pesquisa na área da educação, uma vez que grande parte dos ganhadores de prêmios do Conselho Nacional de Desenvolvimento Científico e Tecnológico $(\mathrm{CNPq})$ pertencem às áreas científicas ligadas à Física, à Matemática, à Nanotecnologia, confirmando que a "ciência para o governo brasileiro, é sempre ciência aplicável na geração de tecnologia que, nas perspectivas neoliberais, está associada ao desenvolvimento social"'.

Mesmo assim, é possivel evidenciar o avanço na legitimação da temática no meio acadêmico como objeto de estudo, dado pela representatividade dos cursos de pós-graduação (strito sensu), sobretudo, os da modalidade profissional, tendo em vista o seu fortalecimento enquanto área/linha de pesquisa e a inscrição de novos pesquisadores, conforme demonstra, a diante, a Figura 5.

Ainda nesse contexto, destaca-se a recente contribuição dos cursos de pós-graduação (strito sensu), da modalidade profissional, voltados à Educação Profissional e Tecnológica, os quais são ofertados tanto pelas Instituições de Ensino Superior quanto pela Rede Federal de Educação Profissional, Científica e Tecnológica (RFEPCT), desde 2016. Dentre esses, destacam-se o Programa de PósGraduação em Educação Profissional Tecnológica (PPGEPT), da Universidade Federal de Santa Maria, e o Programa de Pós-Graduação em Educação Profissional e Tecnológica (ProfEPT), um programa de Mestrado Profissional em Educação Profissional e Tecnológica em rede nacional.

Os mestrados profissionais, sobretudo, os da área da Educação são uma demanda que da Capes, a fim de qualificar professores da rede pública que estão em serviço, principalmente, os da educação básica. Uma vez que geram produtos e processos educacionais para implementação em condições reais nas escolas públicas do país, o que consequentemente, pode melhorar a qualidade do ensino, conforme Documento de Área: Ensino, expedido pela Capes, em 2013. 
Figura 5: Tipos de programas de pós-graduação das produções acadêmicas.

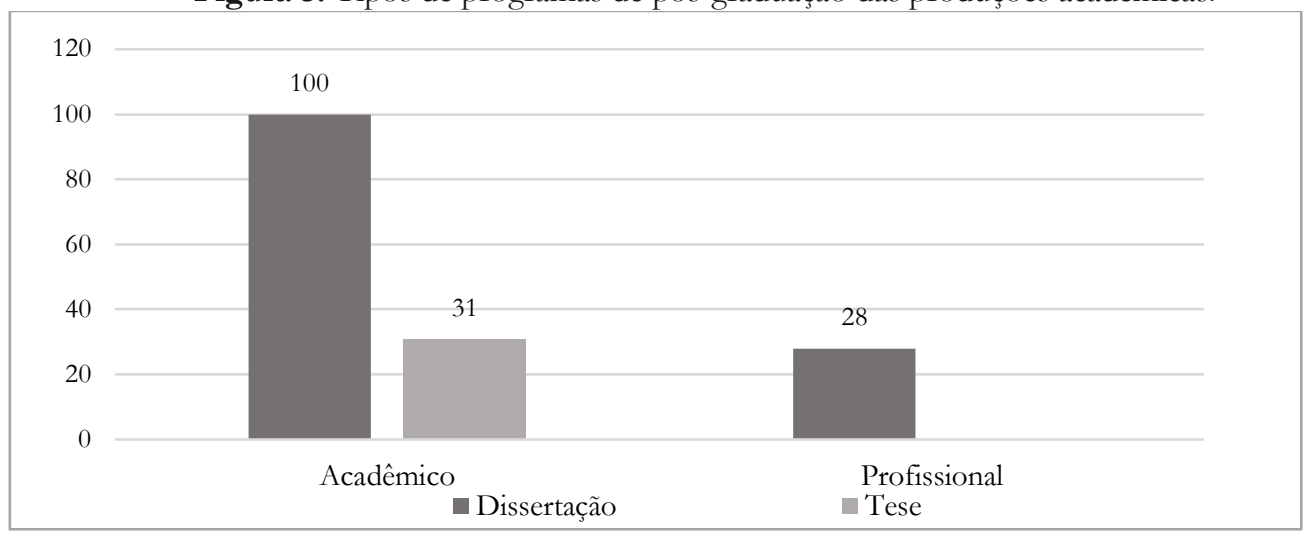

Fonte: os autores.

$\mathrm{Na}$ análise dos Programas de Pós-Graduação, além das modalidades, categorizou-se outro ponto, que reside na área de concentração das produções acadêmicas. Assim, a Figura 6 apresenta um panorama geral sobre as áreas de concentração das teses e dissertações, as quais foram definidas a partir da especificação nominal apresentada pelas próprias produções, isto é, a partir da entidade e do programa proponente, disponibilizados na capa do manuscrito. Ao mesmo tempo, seguiu-se a classificação instituída pelas Capes, a qual é dividida em quatro níveis, do mais geral ao mais específico, sob abrangência das grandes áreas, áreas, subáreas e especialidades do conhecimento.

Em virtude disso, optou-se por categorizar as produções acadêmicas que aparecem em número menor, a partir das grandes áreas do conhecimento, tais como: Linguística, Letras e Artes, Ciências Humanas, Ciências Sociais Aplicadas, Ciências Exatas e da Terra. Também categorizaram-se, nas áreas de conhecimento, aquelas produções que apresentaram um volume mais significativo, como é o caso da Educação, do Ensino, da Interdisciplinaridade e da Educação Física.

Figura 6: Àrea de concentração das produções acadêmicas.

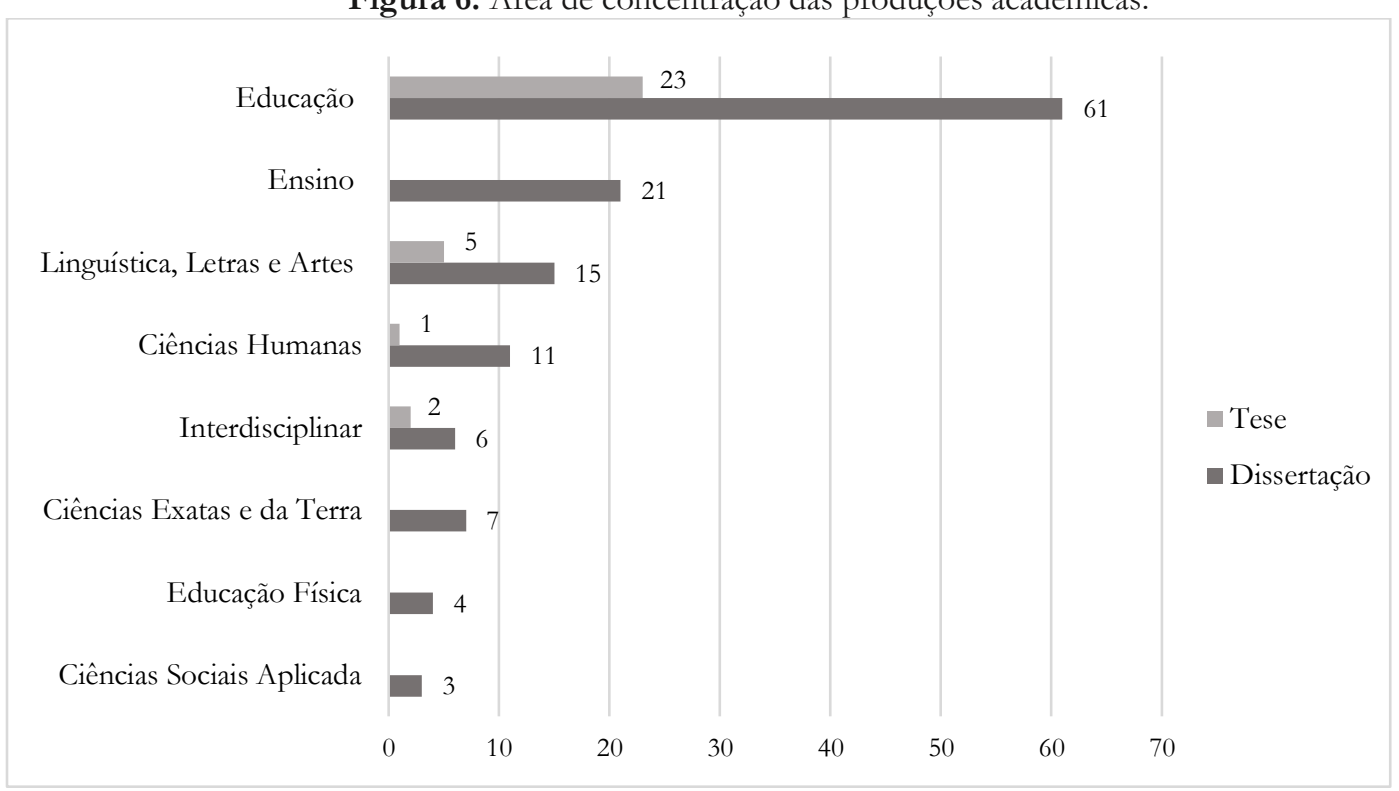

Fonte: os autores.

Percebe-se que a maioria das produções acadêmicas se concentra na área de Educação, chegando a 61 dissertações (47,6\%). De forma mais detalhada, cerca de 51 dessas dissertações (83,6\%) são oriundas de Programas de Pós-graduação em Educação - Mestrado Acadêmico, abrangendo a grande área de conhecimento. Nesse aspecto, destacam-se os cursos da Universidade Federal da Bahia (12 dissertações) e da Universidade de Brasília (11 dissertações). Já as subáreas são exemplificadas pelos cursos de: Educação em Ciências (UNIJUI); Educação Brasileira (UFC); Educação Contemporânea 
(UFPE); e Educação Profissional (UNB). E, as outras 10 dissertações (16,3\%) provêm de Programas de Pós-graduação em Educação- Mestrado Profissional, que envolvem o Profissional em Educação (UFBA), o Profissional em Formação de Professores (UEPB), entre outros.

Esses dados refletem as constatações realizadas pelos autores Lievore, Picinin e Pilatti (2017) que sinalizam para a Educação como um dos três programas de pós-graduação que apresentaram o maior número de expansão passando de 36 programas, em 1998, para 152, em 2014, crescendo 322,22\%. Assim, torna-se a maior área formadora de mestres e a segunda com o maior índice na formação de doutores. No total, foram 34.340 mestres e 9.427 doutores titulados, entre 1998 e 2014.

Além dos Programas de Pós-graduação em Educação, predominam também os da área de Ensino, com 21 dissertações (16,4\%), oriundas, principalmente, dos Programas de Pós-Graduação em Ensino de Ciências e Matemática, de distintas instituições, tais como: UFAL, UFAM, UFC e UFPel. E, também dos Programas de Pós-Graduação Profissionais em Ensino na Saúde, da Universidade Federal Fluminense, e em Ensino de Ciências, da Universidade de Brasília e da Universidade Federal do Pampa. Lievore, Picinin e Pilatti (2017) destacam que a área de Ensino teve o maior crescimento percentual entre todas as áreas do conhecimento na pós-graduação, em virtude das demandas e dos desafios da educação básica. O mestrado profissional constitui-se como o ponto-chave desse processo.

Em relação às teses, pode-se observar que as 23 produções correspondem a 74,1\% do total, advêm do Programa de Pós-graduação em Educação (doutorado acadêmico), com destaque para os cursos da USP, UNINOVE, UNISINOS, PUC/GO e UFES, seguidos pela área da Linguística com 05 teses (16,1\%), cadastradas nos programas da UEL, UFF, UFBA, UNB e UNESP.

O crescimento dos Programas de Pós-graduação, nas áreas da Educação e do Ensino, se reflete no avanço das produções acadêmicas-dissertações e teses, acerca do Ensino Médio Integrado. No entanto, diversos autores chamam atenção para o período de estagnação que se inicia na pós-graduação, principalmente, no que tange às políticas rigorosas da Capes e à redução de recursos financeiros, repassados às universidades federais, acentuadas pelas novas demandas dos contextos emergentes (LIEVORE; PICININ; PILATTTI, 2017).

Dessa forma, para Zancan e Bolzan (2017), as instituições de ensino superior precisam definir novas diretrizes e estabelecer outras estratégias para dar continuidade aos Programas de Pósgraduação e garantir a produção científica e tecnológica, especialmente, em algumas áreas do conhecimento. Esse é o caso, por exemplo, da Educação e do Ensino que necessitam de uma visibilidade permanente no cenário nacional, pois "há muito que avançar, sobretudo, no que se refere ao financiamento, à qualidade da produção e à divulgação", como complementa Ferreira (2009, p. 52).

Quanto à distribuição das produções acadêmicas por região, destacam-se as regiões Nordeste $(32,8 \%)$ e Sul $(26,5 \%)$ as quais possuem a maior parte, $59,3 \%$ (76) das dissertações. E, o maior volume de teses tem as instituições de origem situadas na região Sudeste $(41,9 \%)$, seguido pela região Sul (22,5\%) e Centro-Oeste (19,3\%), como é possível observar na Figura 7, abaixo:

Figura 7: Distribuição das produções acadêmicas por região.

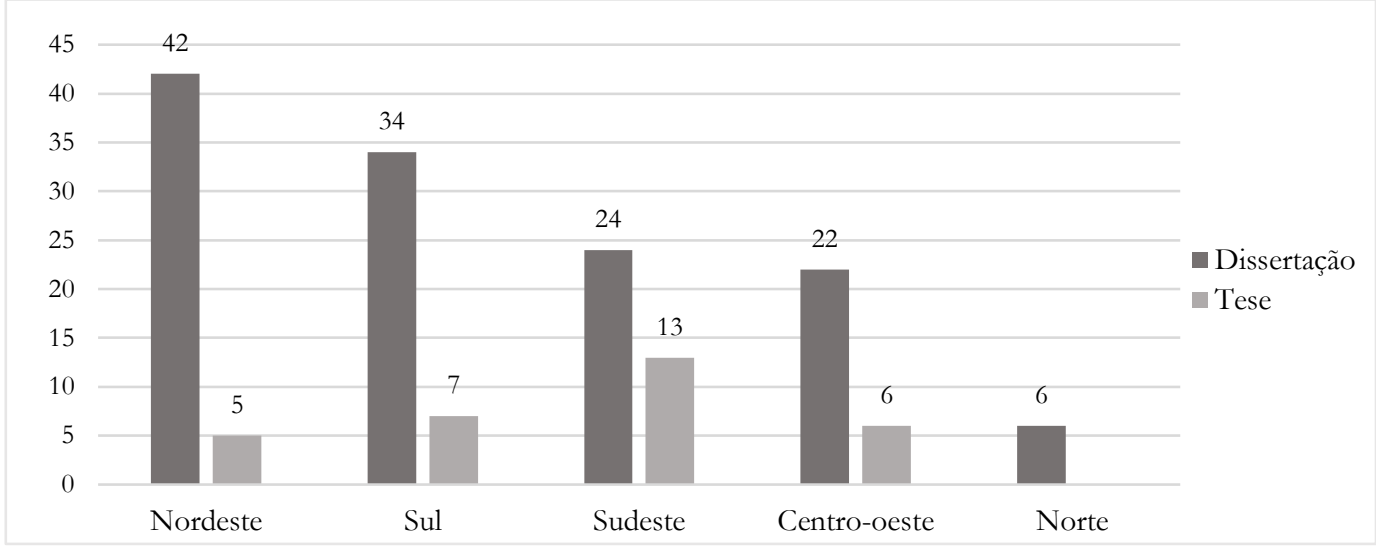

Fonte: os autores. 
Tendo em vista esse estudo, percebeu-se que o maior número de trabalhos concentra-se na região Nordeste que totatiza cerca de 47 (29,5\%), seguida por 41 (25,7\%) advindos da região Sul e 37 $(23,2 \%)$ da região Sudeste. Esse cenário coloca em contraponto a hegemonia das regiões Sul e Sudeste na produção de conhecimento acadêmico-científico. Ressalta também a presença de instituições emergentes, fora do eixo geográfico e central de produção econômica do país, com produções mais preocupadas com o compromisso social do que com os parâmetros científicos de "referência", dados pelas agências financiadoras.

Nota-se que a desigualdade regional científica tem passado por mudanças, em virtude da expansão da pós-graduação no país. Entre 2006 e 2017, o total de programas passou de 2.265 para 4.296, sendo mais expressivo nas regiões com maior carência de ofertas de formação, ou seja, na região Norte $(154 \%)$ e nas regiões Nordeste e Centro-Oeste (125\%), conforme aponta os dados da Capes. Essa tendência de descentralização da produção do conhecimento fica visível na Figura 5, onde a região Nordeste abarca 42 dissertações, a região Centro-Oeste abrange cerca de 22 dissertações, e a região Norte contém 06 dissertações que não apareciam em muitos estudos semelhantes sobre a produção do conhecimento acerca de uma determinada área.

Desse modo, tal panorama não corrobora com o cenário encontrado pela análise da produção de conhecimento da Educação Física brasileira, no período de 1987 a 2010, realizada por Coutinho et. al (2012). Pois, a maior presença de grupos de pesquisa, cadastrados no CNPq, e programas de pós-graduação, reconhecidos pela Capes, localiza-se na região Sudeste, seguida pela Sul.

Em complemento, analisou-se também a contribuição das Instituições de Ensino Superior (IES) diante da produção de conhecimento sobre o Ensino Médio Integrado. Com relação às dissertações, destacam-se a Universidade Federal da Bahia (UFBA) com 17 trabalhos, sendo a maioria (12) oriundos dos dois programas de pós-graduação em Educação (acadêmico e profissional), e também a Universidade de Brasília (UNB) com 16 trabalhos. Sobre as teses, sobressaem-se a Pontifícia Universidade Católica de Goiás (PUC/GO) e a Universidade de São Paulo (USP). A distribuição das teses e dissertações publicadas pelas IES, com as maiores representatividades, está apresentada na Figura 8.

Figura 8: Distribuição das produções acadêmicas por instituições de ensino.

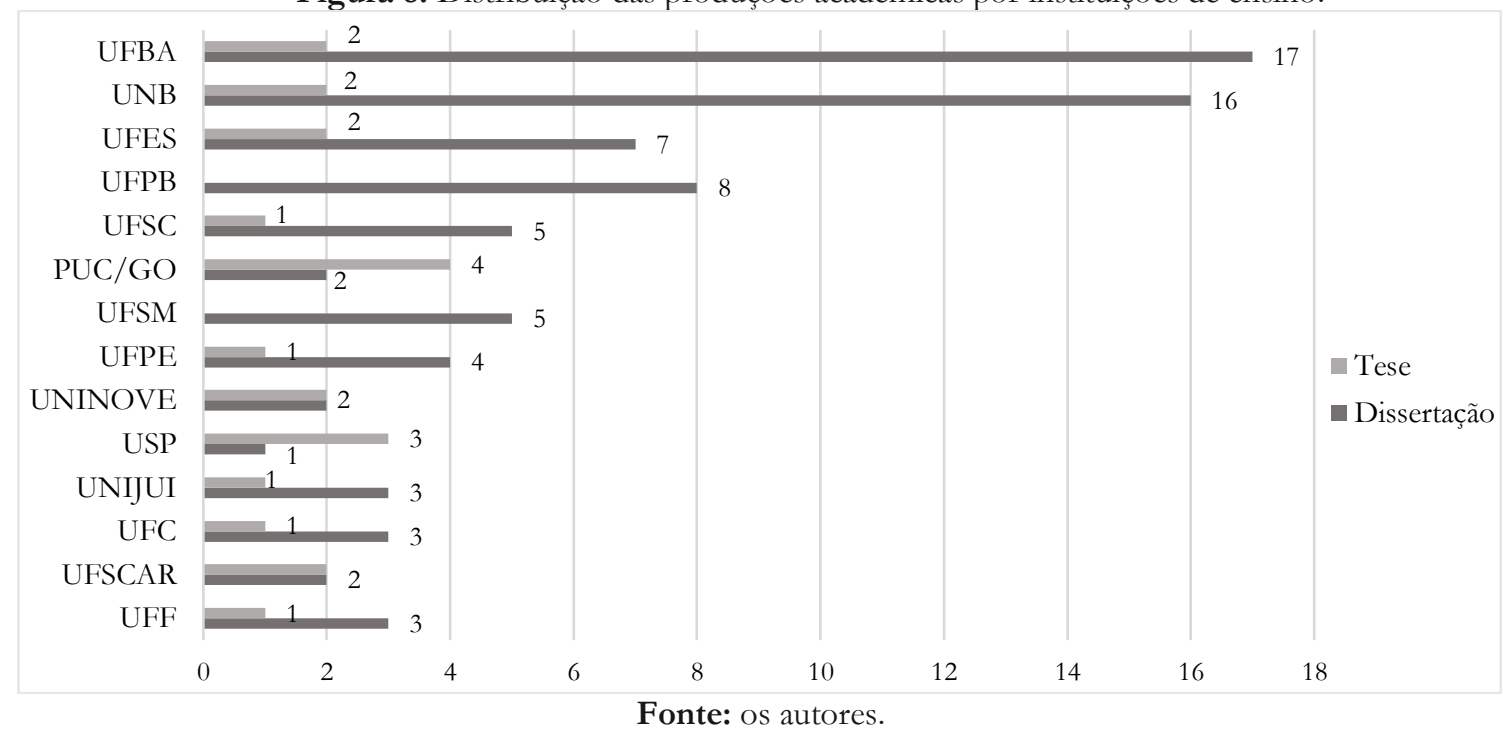

Posteriormente a essa sistematização do panorama geral das produções acadêmicas sobre o Ensino Médio Integrado, parte-se para a configuração da sua matriz analítica, em correspondência com Coutinho et al. (2012). Essa configuração está centrada na categorização, referente à natureza, abordagem do problema, aos procedimentos técnicos (instrumentos de coleta e análise dos dados) e ao delineamento da temática, do público-alvo e do lócus das 128 dissertações e 31 teses. Tal procedimento possibilita a associação dos resultados e a produção de interpretações fundamentadas na interação entre a análise quantitativa e qualitativa. 


\section{Avaliando a produção de conhecimento sobre o ensino médio integrado: o que mostram as produções acadêmicas}

Os estudos acerca do Ensino Médio Integrado vêm aumentando expressivamente, da mesma forma que os temas, enfoques e contextos estão se diversificando. Diante disso, buscar-se-á conhecer e compreender como estão sendo estruturadas as produções acadêmicas, a fim de contribuir com a relevância científica e social enquanto objeto de estudo.

Inicialmente, analisaram-se as produções acadêmicas quanto a sua natureza que, conforme Gil (2010) dividem-se em quatros categorias: a pesquisa básica pura,- destinada unicamente à ampliação do conhecimento; a pesquisa estratégica - voltada à aquisição de novos conhecimentos, com vistas à solução de reconhecidos problemas práticos; a pesquisa aplicada- destina-se à construção de conhecimento, voltados à aplicação numa situação específica; e o desenvolvimento experimental que se refere ao trabalho sistemático, direcionado à produção de novos materiais, equipamentos, políticas ou à melhoria de novos sistemas e serviços.

Para essa categorização utilizaram-se: a pesquisa básica, a pesquisa aplicada e a pesquisa estratégica, em virtude das características especificadas e das finalidades dos estudos, como pode ser visualizado, na Figura 9.

Figura 9: Classificação quanto à natureza das produções acadêmicas.

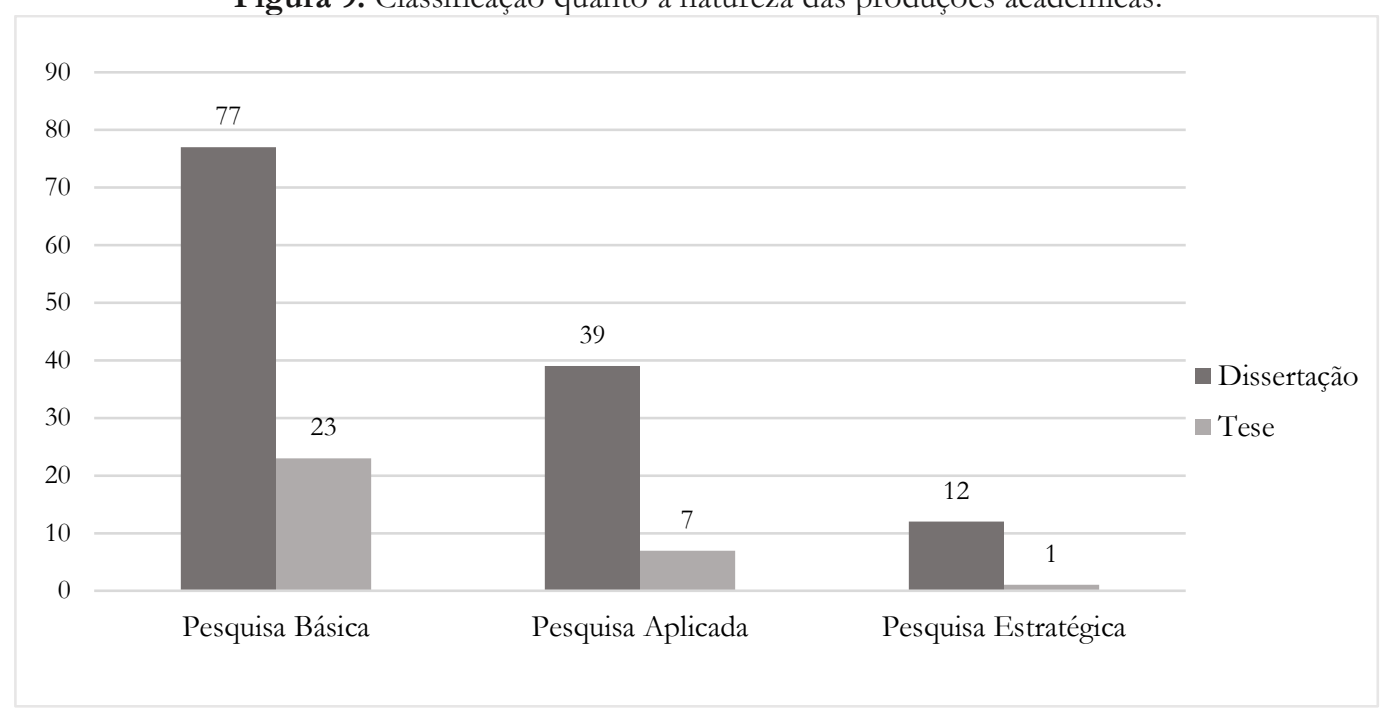

Fonte: os autores.

Nota-se, a partir da Figura 9, que a maioria (62,8\%) das produções acadêmicas (dissertações e teses) permeiam os elementos de uma pesquisa básica, pois geram novos conhecimentos, mas não têm uma imediata intervenção na realidade. É conduzida "no sentido de reconstruir teorias, quadros de referência, condições explicativas da realidade, polêmicas e discussões pertinentes" (DEMO, 2000, p. 20).

A título de ilustração, as 77 dissertações e as 23 teses fazem um diagnóstico e, por conseguinte, teorizam a realidade. Como é o caso da dissertação de Matos (2017) que analisou o papel atribuído à escola na construção de projetos de futuro pelos alunos do Ensino Médio Integrado do Instituto Federal de Sergipe - Campus de Aracaju. Porém, ao final do texto, a pesquisa não sinalizou como contornar as constatações de que escola é vista como um obstáculo, uma necessidade imposta aos alunos. É, portanto, uma etapa que tem que ser passada.

A tese de Dias (2015) buscou compreender o que é a educação integrada: a definição, características, finalidades sociais e políticas, referencial teórico-metodológico e fundamentos pedagógico-didáticos. Está pautada em uma análise teórica da educação e da pedagogia socialista, juntamente com uma análise teórico-documental da legislação.

Nesse enredo, sinaliza-se para o abismo entre a pesquisa educacional e a escola, consolidando a dicotomia entre a teoria e a prática e o distanciamento existente na relação entre a pesquisa, as políticas 
educacionais e as práticas pedagógicas. Gatti (2002, p. 33), ao avaliar os impactos da pesquisa educacional nas reformas e inovações educacionais, e nos sistemas estaduais de educação, constatou a "insuficiente participação das instituições de ensino superior nos projetos de desenvolvimento ou inovações do sistema educacional, bem como pouca utilização das pesquisas educacionais". Isso se justifica por alguns fatores como: o distanciamento das universidades em relação aos problemas práticos; a visão idealizada e teórica da universidade sobre o ensino; a falta de maior procura por parte dos órgãos governamentais em relação à universidade; o caráter teórico das pesquisas; a falta de comunicação dos resultados das pesquisas, entre outros.

Em sua reflexão, Goergen (1986, p. 12) assinala que o conhecimento propiciado pela pesquisa educacional é movido, ou deve ser movido, pelo interesse e pela necessidade de transformação da realidade, ou seja, a pesquisa tem importância em si, mas não se esgota em si, ela é também meio para assegurar o seu papel social. De tal modo, deve-se ampliar a "cooperação entre os pesquisadores educacionais e os administradores da política educacional", sem perder de vista que a pesquisa e a ação política-pedagógica se dão em compassos diferentes, pois não seguem um "fluxo natural entre o conhecimento adquirido através da pesquisa e uma nova prática”.

$\mathrm{Na}$ sequência, destaca-se as $46(28,9 \%)$ dissertações e teses, que transitam pelo viés da pesquisa aplicada, as quais tinham como intenção transformar os resultados do estudo em ações concretas. Dentre essas, está a dissertação de Fernandes (2015) que aplicou uma sequência didática, com atividades de simulação computacional do Grupo PHET, da Universidade do Colorado (EUA). Nesse trabalho, atividades experimentais, desenvolvidas pelos alunos, com material de baixo custo e experimentos envolvendo noções básicas de eletrônica e programação, por meio da plataforma microcontrolada Arduino, visaram contribuir com a diminuição das dificuldades de ensino-aprendizagem diante dos conceitos de eletricidade. Esse processo, unificou teoria e prática em situações que poderão ser utilizadas no cotidiano e indicia a aprendizagem significativa dos conceitos de eletricidade, consequentemente, da física.

A tese de Borges (2016) objetivou trazer novas sugestões de atividades práticas para o ensino de leitura, exemplificadas através das oficinas realizadas com alunos dos $1^{\circ}$ anos e $3^{\circ}$ anos, sob a migração do "restritivamente linguístico" ao "globalmente comunicativo".

Esse aparecimento significativo de produções acadêmicas com a intenção de aplicação na realidade vai ao encontro da indispensável relação entre a pesquisa e o ensino, defendida por Freire (1996, p. 29) para o qual "não há ensino sem pesquisa e pesquisa sem ensino. Esses que-fazeres se encontram um no corpo do outro. Enquanto ensino contínuo buscando, reprocurando. Ensino porque busco, porque indaguei, porque indago e me indago".

Tal relação é elucidada pelo diálogo entre a atividade investigativa e o cotidiano educacional, que vem sendo firmando entre os sujeitos envolvidos com o Ensino Médio Integrado e a universidade, já que a grande parte dos autores das dissertações e teses são professores ou técnicos-administrativos dos IFs. Assim, percebeu-se que, ao adotarem o Ensino Médio Integrado como objeto de estudo, os pesquisadores buscam refletir, compreender e transformar suas realidades, ou seja, as situações divergentes da prática, vividas nos IFs, a partir das teorias, que são sistematizadas e compartilhadas pelo meio acadêmico. Tal perspectiva pode se aproximar da formação de um profissional reflexivo que se constrói nessa prática reflexiva, defendida por Schon (1992). Essa formação ocorre sob três ideias centrais: a reflexão-na-ação, a reflexão sobre-a-ação e a reflexão-sobre-a reflexão-na-ação.

Nesse sentido, Freire (1996, p. 24) assinala sobre a importância de a prática ser reconstruída constantemente, em concordância com a teoria, visto que a "reflexão crítica sobre a prática se torna uma exigência da relação teoria/prática sem a qual a teoria pode ir virando blábláblá e a prática, ativismo". Com base nessas compreensões, as 46 produções acadêmicas, com o viés da pesquisa aplicada, apresentam as práticas pedagógicas inovadoras, que são significativamente diferentes, caminhando em direção a efetivação da transformação qualitativa, mediante a uma teoria e uma práxis educativa emancipatória, como propõe Mészáros (2008).

No que tange à pesquisa estratégica, obtiveram-se 13 produções acadêmicas, cerca de 8,1\%, que evidenciam um dos resultados dos mestrados profissionais, em virtude da exigência da constituição de um produto educacional para ser aplicado imediatamente ou proposta de solução das demandas 
educacionais. Como exemplo, tem-se a dissertação de Feitosa (2018), que versou sobre a questão permanência no Ensino Médio e propôs uma escola mais acolhedora, por meio da criação do "Laboratório de Estudos e Práticas Pedagógicas". Esse constitui-se como um possível espaço de reflexão sobre as práticas profissionais, das práticas pedagógicas vivenciadas na instituição, das relações estabelecidas entre construção de conhecimento e o aluno, das relações construídas e mantidas entre docentes/alunos/técnicos e comunidade.

Lançando o olhar, agora, para a classificação quanto à abordagem do problema, qualitativa e/ou quantitativa, apesar da dualidade histórica estabelecida entre os dois métodos, buscou-se agrupar os estudos a partir dos apontamentos de Creswell (2007, p. 22), que sinalizam para uma posição e distinção "menos qualitativa versus quantitativa e mais sobre como as práticas de pesquisa se posicionam entre estes dois polos, ou seja, podemos dizer que os estudos tendem a ser mais qualitativos ou mais quantitativos". Desse modo, as produções acadêmicas estão agrupadas como: pesquisa quantitativa, pesquisa qualitativa e pesquisa quali-quantitativa, como consta na Figura 10.

Figura 10: Classificação quanto à abordagem das produções acadêmicas.

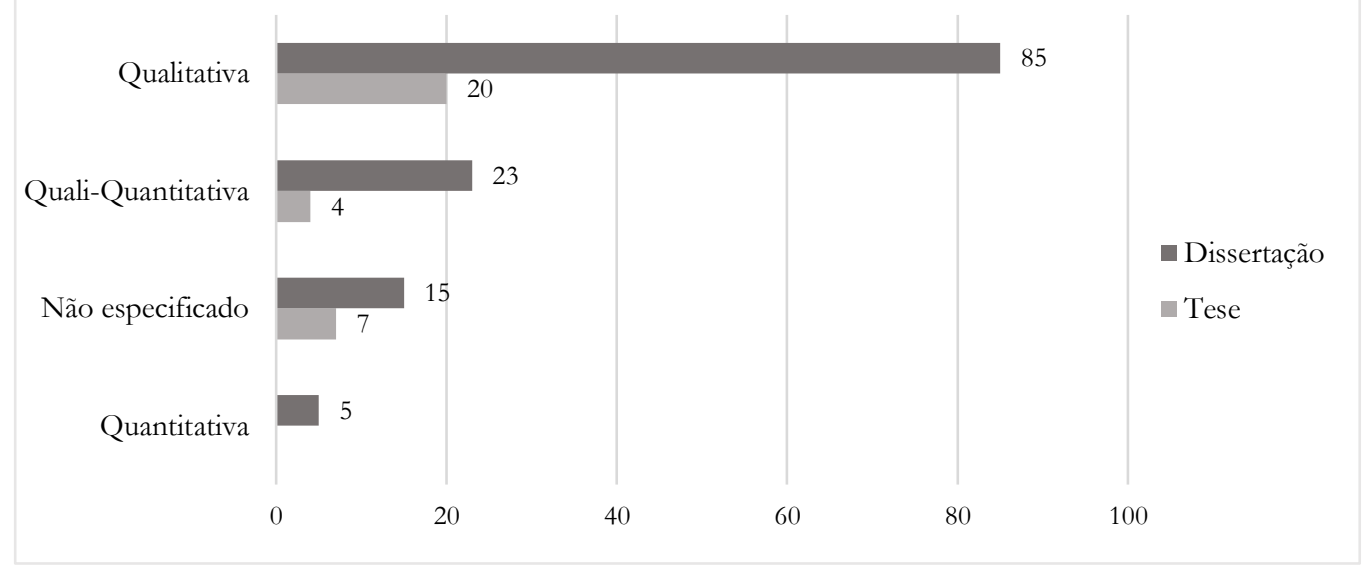

Fonte: os autores.

O quantitativo das dissertações e teses, pontuado na Figura 8, mostra que a maioria perpassa pela abordagem qualitativa, uma vez que é a mais utilizada, em se tratando de estudos sobre a educação. A pesquisa qualitativa, segundo Minayo (2010), "busca questões muito específicas e pormenorizadas, preocupando se com um nível da realidade que não pode ser mensurado e quantificado", isto é, procura compreender o fenômeno a partir das atitudes, das falas, das crenças, dos valores, dentre outras características subjetivas, considerando que há uma relação dinâmica entre o mundo real, o sujeito e a subjetividade do sujeito, sendo traduzido por números, mas sim por concepções, entendimentos e discursos.

Nessa perspectiva, as 105 (66\%) produções acadêmicas foram orientadas pelos critérios da pesquisa qualitativa, pois objetivaram entender o Ensino Médio Integrado como fenômeno social, diante da sua totalidade, historicidade e complexidade, por meio da utilização de narrativas e de transcrições literais de verbalização dos sujeitos. Conforme abordou Correia (2018), ao compreender quais são os significados que os participantes atribuem ao fenômeno, ou seja, quais são os sentidos da política de assistência estudantil para estudantes do ensino médio integrado do Instituto Federal da Bahia - Campus Jacobina, no período temporal de 2014 a 2017.

Segundo Bogdan e Biklen (1994), na abordagem qualitativa, os pesquisadores buscam compreender os significados sobre as experiências e os contextos, a partir do ponto de vista do outro, em um exercício de diálogo, que não pode ser feito de forma neutra. No entanto, Thesing e Costas (2017, p. 1843) chamam atenção para crítica acerca da falta de rigor científico diante da sua natureza e validade, o que derivaria "processos investigativos com análises ametódicas e generalistas. Questiona-se o nível de cientificidade dessas pesquisas, essas apontadas como meras descritoras da realidade, sem o desenvolvimento de uma interpretação científica das realidades". 
Para que o papel do pesquisador e a validade científica das pesquisas qualitativas não passem a ser colocadas em xeque, André (2013) pontua a importância de descrever de forma clara e concisa à organização do caminho investigativo, bem como as escolhas metodológicas feitas pelo pesquisador, demonstrando o rigor e a cientificidade na coleta e na análise dos dados.

Além disso, 16,5\% (27) das dissertações e teses abordam o problema de pesquisa a partir da combinação entre o qualitativo e quantitativo, o que têm ganhado visibilidade nos últimos anos, conforme visualizamos nas dissertações de Veiga (2016); Bresolin (2016); Gusmão (2016); Barros (2015); Soares (2015); Zukowsi (2013); Bezerra (2012); Bentes (2009); e na tese de Marçal (2015), pois o pesquisador aprende a combiná-las, diante das necessidades, de forma rigorosa no momento de integrar as evidências encontradas, percebendo-os como complementares.

A complementaridade entre os dois tipos de abordagem qualitativa e quantitativa é entendida como uma das saídas possíveis para a compreensão da complexidade concreta dos fenômenos em educação, que, no caso desta investigação, é o Ensino Médio Integrado. Por isso, Creswell (2007) compreende que, no método misto, a coleta de diversos tipos de dados garante um entendimento melhor do problema pesquisado.

Gatti (2004, p. 13) complementa que essa combinação pode "vir a enriquecer a compreensão de evento, fatos, processos. As duas abordagens demandam, no entanto, o esforço da reflexão do pesquisador para dar sentido ao material levantado e analisado", ultrapassando as fronteiras que as separam e aproveitando as suas qualidades.

Nesse mesmo sentido, Goldenberg (2004) também defende a utilização das duas abordagens, pois:

\footnotetext{
"nenhum pesquisador tem condições para produzir um conhecimento completo da realidade, diferentes abordagens de pesquisa podem projetar luz sobre diferentes questões. É o conjunto de diferentes pontos de vista, e diferentes maneiras de coletar e analisar os dados (qualitativa e quantitativamente), que permite uma ideia mais ampla e inteligivel da complexidade de um problema." (GOLDENBERG, 2004, p. 61).
}

Em relação a esta investigação, salienta-se que apenas 3\% (5) das dissertações ocuparam-se da abordagem quantitativa, ao utilizarem indicadores numéricos para discutir a questão - foco e analisar o fenômeno, predominando as representações gráficas. Nesse contexto, evidencia-se a dissertação de Pinto (2015), que para analisar a relação entre as características individuais do perfil socioeconômico e do desempenho dos alunos dos cursos de ensino médio integrado do Instituto Federal da Bahia-Campus Barreiras, tratou os dados, sob as técnicas estatísticas, utilizando o software SPSS.

Para Gatti (2004), no Brasil, há poucos estudos sobre essa abordagem, apesar de alguns problemas educacionais que, para a sua contextualização e compreensão, pedem estudos com análise quantitativa. A pouca adesão em relação a essa abordagem pode ser justificada pelo fato de que a "mensuração pode deslocar a informação de seu contexto original” (CASTRO et al., 2010, p. 343), uma das suas maiores limitações.

Em concordância com a abordagem do estudo para conhecer e interpretar os processos e os contextos do Ensino Médio Integrado, têm-se os procedimentos técnicos, que definem o passo a passo intencional da coleta e da análise dos dados, resultando em respostas para as indagações iniciais. Nessa direção, ao se desconsiderarem as 65 produções acadêmicas que não especificaram os procedimentos técnicos empregados, um dado significativo é que grande parte se apresenta de forma empírica, isto é, enquadra-se em exploratória, descritiva ou experimental, apesar de utilizarem teorias e documentos, poucas assentam-se, unicamente, na pesquisa bibliográfica e/ou documental.

Assim, a classificação mais detalhada, quanto aos procedimentos técnicos das produções acadêmicas, estruturou-se na Figura 11. 
Figura 11: Principais metodologias das produções acadêmicas.

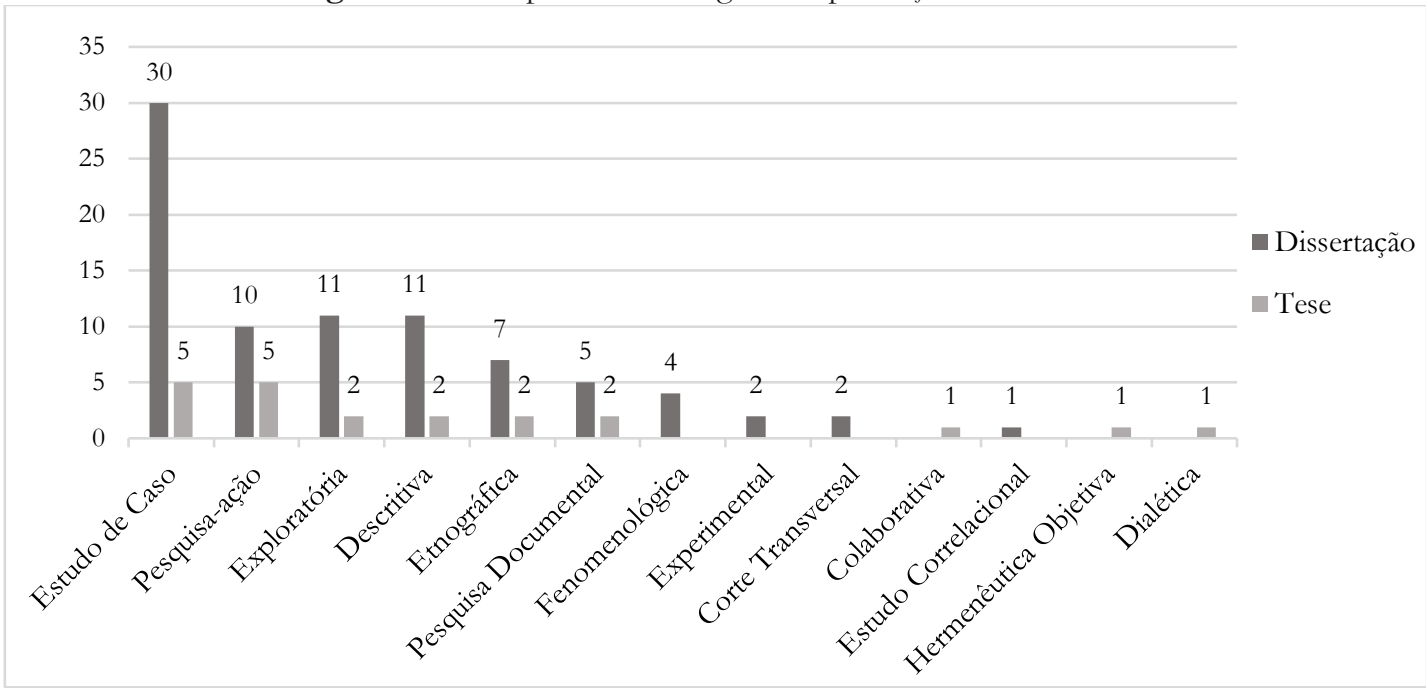

Fonte: os autores.

Como apresentado na Figura 11, dentre as pesquisas empíricas, houve a predominância do tipo estudo de caso $(37,2 \%)$, além do destaque para a pesquisa-ação $(15,9 \%)$, sinalizando a prevalência da abordagem qualitativa nas produções acadêmicas, conforme explicitado, anteriormente, na Figura 8. Segundo André (2005), com a consolidação da pesquisa qualitativa na educação, advém uma gama de tipologias metodológicas. Essas novas propostas de abordagem são definidas como: pesquisa participante, pesquisa-ação, pesquisa etnográfica, estudo de caso e história de vida.

O estudo de caso é uma "descrição intensiva, holística e uma análise profunda de uma entidade singular, um fenômeno ou unidade social" (MOREIRA, 2011, p. 87). Nesse delineamento, as produções acadêmicas analisadas, de certa forma, realizaram estudos aprofundados sobre os projetos de vida dos alunos, os programas de evasão e permanência, o planejamento e as metodologias de ensinoaprendizagem e a implementação do Ensino Médio Integrado.

Sobre a pesquisa-ação, Thiollent (1985) caracteriza-a pelo e no relacionamento de dois tipos de objetivos: prático e de conhecimento. O objetivo prático é voltado para o levantamento de soluções e possibilidades de ações relacionadas ao objeto de estudo. O objetivo de conhecimento é a obtenção de informações e a ampliação de conhecimento no campo da ciência. Dessa forma, segundo Baldissera (2001, p. 25) "na pesquisa-ação acontece simultaneamente o "conhecer" e o "agir", uma relação dialética sobre a realidade social desencadeada pelo processo de pesquisa".

Essa estratégia de investigação, interpretação, participação e transformação da realidade pode ser exemplificada pela dissertação de Ximenes (2017), que propôs um plano de ação pedagógica para o ensino de geografia, a partir da metodologia da Educação Patrimonial, amparada na literatura de cordel, aos alunos e professores do Instituto Federal da Paraíba. E, pela tese de Leite (2013), que para compreender como se desenvolve a educação estética em jovens, mediada pela arte, proporcionou intensos, diversificados e contínuos encontros com obras de arte; mediou leituras de imagens; e também realizou experimentações artísticas, que recriam a técnica utilizada pelo artista estudado, como professorpesquisador, junto com os alunos.

Ainda com relação aos procedimentos técnicos, propôs-se observar nas produções acadêmicas os tipos de instrumentos de coletas e análise dos dados, conforme se estruturou na Figura 12. 
Figura 12: Principais instrumentos utilizados pelas produções acadêmicas.

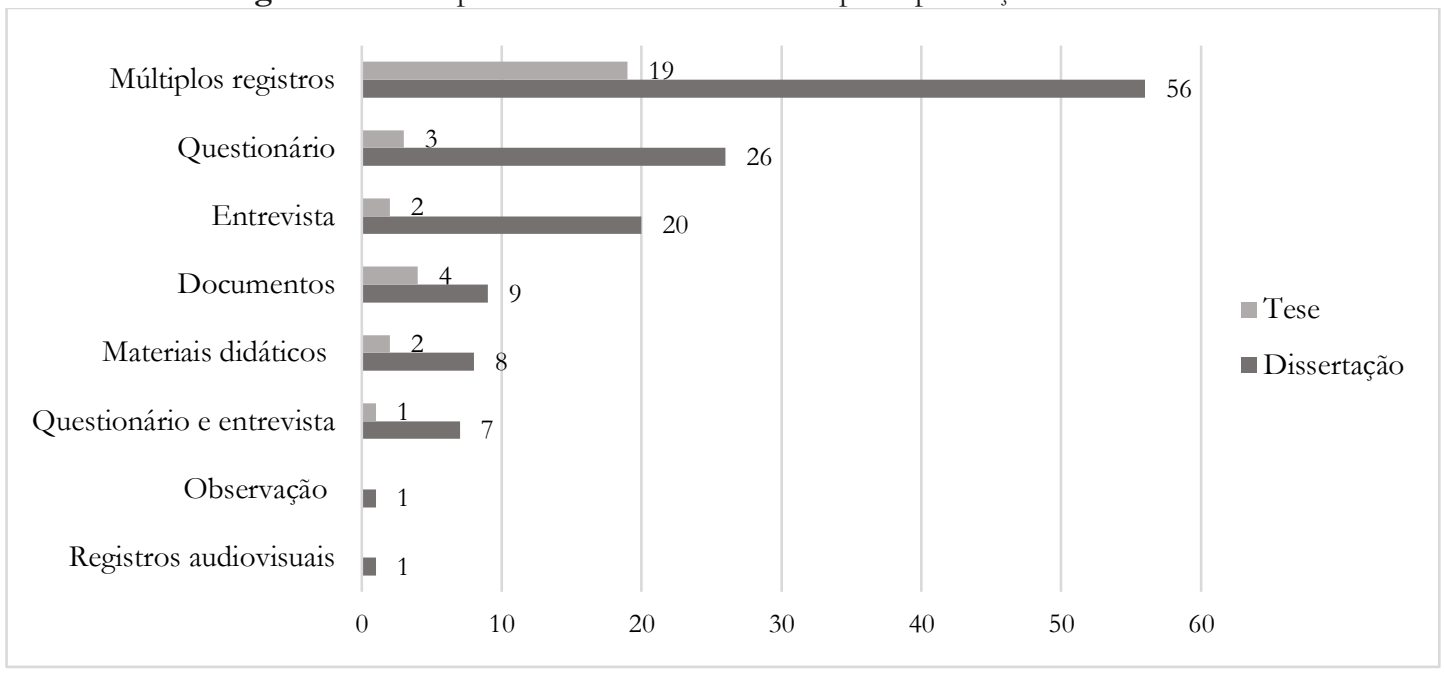

Fonte: os autores.

As produções acadêmicas, em sua maioria (47,1\%), utilizaram múltiplos registros (documentos oficiais, documentos institucionais, questionário, entrevista, diário de campo, fotos, áudios, encontros, materiais didáticos, oficinas e filmagens) como fonte de informação, em consonância com a predominância da abordagem qualitativa. Além disso, os 29 estudos (18,2\%), aplicaram questionário e, desses, 19 também utilizaram de outras fontes, tais como: documentos, observação, materiais didáticos, para complementar a coleta dos dados, assim como 11, dos 22 trabalhos que empregaram a entrevista.

Para André (2005, p. 06) "ganham força os estudos qualitativos, que englobam um conjunto heterogêneo de métodos, de técnicas e de análises", uma vez que pretendem conhecer e interpretar o fenômeno estudado na sua totalidade, além de demonstrar o rigor científico necessário da pesquisa.

Em complemento à análise, outro ponto observado residiu sobre os principais tipos de procedimentos utilizados para interpretar os dados. Em relação a isso, 26 produções acadêmicas fizeram a escolha pela análise de conteúdo de Bardin (2011), que compreende as etapas de pré-análise (organização dos dados), exploração do material, definições das categorias e interpretação dos apontamentos.

Segundo Strauss e Corbin (2008) tanto a coleta quanto à análise e a interpretação de dados estão relacionadas a escolhas e as decisões a respeito da utilidade dos procedimentos, sejam eles qualitativos ou quantitativos. Porém, a objetividade e a imparcialidade, nas escolhas teóricometodológicas, não significam que as pesquisas tenham neutralidade científica, pois todo método tem uma base epistemológica e filosófica. Isso faz da atividade de pesquisa, assim como a atividade de ensino, um "ato político que se fundamenta em pressupostos de liberdade ou dominação no campo científico. Assim, dependendo da escolha política e ideológica do pesquisador, seus estudos e investigações contribuirão para a transformação ou manutenção da realidade social", como assinalam Thesing e Costas (2017, p. 1840).

Por fim, expõem-se os resultados referentes às temáticas das dissertações e teses, assim, distribuídas na Figura 13. 
Figura 13: Temáticas das produções acadêmicas.

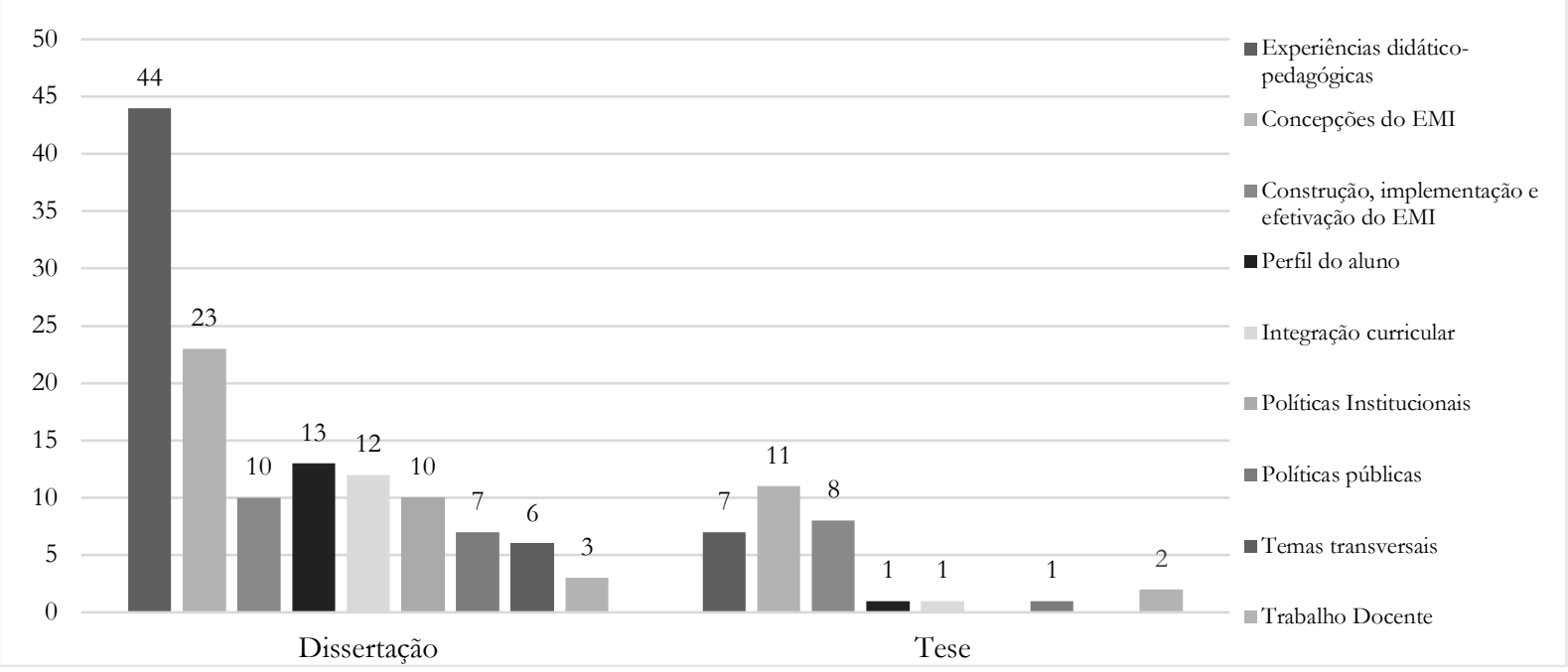

Fonte: os autores.

Com esses resultados, transparece um leque extremamente amplo de temáticas de pesquisas, porém o maior volume das dissertações e teses apresentou como temática central: as experiências didático-pedagógicas, totalizando 32\%. Além disso, as 51 produções acadêmicas analisaram uma situação específica de ensino ou de uma determinada disciplina, principalmente, para melhorar as dificuldades vivenciadas no processo de ensino-aprendizagem, com a utilização de metodologias inovadoras (tema gerador, sequências didáticas contextualizadas, proposta curricular colaborativa, ensino por modelagem, gamificação, oficinas, problematização, projetos, entre outras), e de recursos alternativos (experimentos, plataformas digitais, histórias em quadrinhos, software, resumos, cordel, simulação computacional, produção de vídeos, entre outros). Tais metodologias contrapõem-se à abordagem educacional centrada na exposição do professor, na leitura do livro e na passividade do aluno.

Para elucidar, destaca-se a dissertação de Fernandes (2015) que aplicou uma sequência didática sobre conceitos de eletricidade, por meio de experimentos e atividades de simulação computacional aos alunos do curso de Mecatrônica do Ensino Médio Integrado, de um Instituto Federal, no Rio Grande do Sul. Outro exemplo é a tese de Boscatto (2017) que se centrou na análise da construção colaborativa virtual de uma proposta curricular para a Educação Física, elaborado por seis professores do Instituto Federal de Santa Catarina.

No entanto, dentre essas 51 produções acadêmicas, apenas 09 experiências didáticopedagógicas são orientadas pela perspectiva da interdisciplinaridade e da contextualização. Esse é o caso da dissertação de Della Volpe (2018), que desenvolveu uma alternativa didática, interdisciplinar e contextualizada, utilizando a Ciência, Tecnologia e Sociedade (CTS) e os Hidrofluorocarbonetos (HFC), a partir da química. Outra produção é de Silva (2018), a qual propôs um material didático em Língua Espanhola, relacionando a conservação da agrobiodiversidade e da comida. O terceiro trabalho é de Barreto Filho (2016) que construiu um programa interdisciplinar participativo, a fim de contribuir para a conscientização dos estudantes do $1^{\circ}$ ano do ensino médio quanto à redução do sobrepeso. Essas investigações têm relação com as reflexões de que somente uma "atitude interdisciplinar possibilita avançar no processo de construção de uma prática contextualizada, na qual as ciências se interpenetrem proporcionando novas compreensões da realidade", conforme Fazenda (2011, p. 34).

Nota-se também que $34(21,3 \%)$ dos estudos tratam das concepções do Ensino Médio Integrado, com a finalidade de analisar e discutir seus pressupostos teóricos, representados pela categoria do ensino politécnico, do trabalho, da formação integrada e da flexibilidade curricular, em busca de uma formação humana cidadã e emancipatória, a partir das vozes dos alunos, dos professores, dos gestores e dos coordenadores de diferentes cursos. Contudo, com a predominância das percepções advindas dos professores, como abordado nos estudos de Gianelli (2018), de Garcia (2017), de Rosa (2015), de Figliuolo (2010) e de Bentes (2009). 
Outro destaque se dá para os $18(11,3 \%)$ estudos que abordaram a construção, a implementação e a efetivação do Ensino Médio Integrado nos IFs, uma vez que o Decreto no 5.154/04 apenas apresenta suas bases legais, porém não esclarece como efetivá-lo. Logo, a elaboração, a operacionalização e a avaliação do currículo, da sua proposta pedagógica, dos seus cursos e dos Projetos Pedagógicos dos Cursos (PPCS) têm sido temas pertinentes nas pesquisas, tanto de uma determinada unidade ou quanto do Instituto como um todo, a fim de pontuar as possibilidades, as tensões, as disputas internas, as perspectivas, os limites e os desafios, considerando seus princípios e suas concepções teóricas.

Isso vem sinalizando para o fato de que o Ensino Médio Integrado ainda está em construção, a qual precisa ser coletiva, pois deve-se estabelecer uma relação entre o discurso oficial e a realidade dos seus sujeitos, do prescritivo ao perceptivo. Nesse sentido, Pontes Júnior (2012), em sua tese, procurou analisar como o Ensino Médio Integrado se constitui em seus aspectos institucionais, organizacionais e político-pedagógicos na materialidade do Instituto Federal da Paraíba.

Além disso, apareceram 14 (8,8\%) dissertações e teses com o objetivo de conhecer o perfil dos alunos, isto é, mapear as expectativas e aspirações deles com relação à instituição, à formação e ao projeto profissional e pessoal; as características dos jovens, os comportamentos, os anseios, os desejos e os motivos da escolha pelo Ensino Médio Integrado, a fim de firmar a apropriação dessa escolarização com sentido, ao valorizar a cultura do jovem.

Como exemplo, Silva Filho (2018), em sua dissertação, verificou que os jovens reconhecem a contribuição da formação para a consolidação dos seus projetos, tanto no que se refere aos conhecimentos da área básica quanto aos da área técnica. E, Guedes (2017), em sua tese, demonstrou que os estudantes acreditam ser o Instituto Federal Sul-rio-grandense capaz de auxiliá-los no seu projeto de vida, por meio da qualidade de ensino, do corpo docente; prepará-los para o futuro profissional e, essa preparação vai desde a parte técnica até a propedêutica. $\mathrm{O}$ autor verificou também que, em todos os PPCs, há uma preocupação com a formação integral dos alunos.

Os resultados também evidenciaram que 13 (8,1\%) dissertações e teses voltaram seu interesse para a integração curricular e buscam analisar as percepções dos professores e dos alunos sobre a integração; compreender a relação entre as áreas técnicas e a área básica, assim como a articulação entre a teoria e a prática; retratar a integração, a partir das diretrizes da Educação Profissional e Tecnológica; analisar a implementação do currículo integrado, além de apresentar as propostas de organização curricular, que efetivem a integração, a partir da pesquisa, da extensão, das práticas pedagógicas e experiências integradoras, como é o caso, da Prática Profissional Integrada (PPI), institucionalizada pelo Instituto Federal Farroupilha.

Nessa direção, tem-se 05 estudos que tratam de forma prática a integração curricular, ou seja, evidenciam a sua materialização, por meio da aplicação de práticas integradoras e da construção e implementação do currículo integrado. Dentre essas, destacam-se duas dissertações: a de Bresolin (2016), que investigou os diálogos interdisciplinares da Prática Profissional Integrada (PPI), produzidos pelos alunos do curso Técnico em Química Integrado ao Ensino Médio do IFFar, e a de Smaniotto (2015), que analisou os limites e as possibilidades de articulação entre os conhecimentos técnicos e básicos, e como perpassam o currículo e a formação de um curso Técnico em Química, no contexto da Prática Profissional Integrada (PPI) do IFFar.

Já as investigações com intuito de refletir sobre as políticas institucionais, relacionadas ao Ensino Médio Integrado, totalizaram 10 (10,1\%). Surgiram, com maior intensidade, as pesquisas que tratam da Política de Assistência Estudantil, nos IFs, a qual visa contribuir, nos termos do Decreto $\mathrm{n}^{\circ} 7234 / 2010$, para o acesso, a permanência e a conclusão dos cursos, reduzir os índices de retenção e evasão escolar e, com isso, melhorar o desempenho acadêmico, por meio da distribuição de bolsas e auxílios, além do apoio pedagógico para o atendimento integral do aluno. Por isso, o diagnóstico do perfil socioeconômico e do desempenho dos alunos; as propostas de programa de evasão, permanência e êxito; as estratégias de prevenção a evasão; e as ações de permanência, como é o caso do programa de incentivo ao esporte e lazer, têm sido uma preocupação dos estudos, conforme apresentado por Correia (2018), Veiga (2017), Silva (2017), Zibenberg (2016) e Pinto (2015). 
Com relação às demais temáticas, 08 produções acadêmicas referem-se às políticas públicas do Ensino Médio Integrado, como evidencia a dissertação de Silva (2017) intitulada: "A formação humana integral e o ensino médio (integrado) no contexto das reformas educacionais (2016-2017): uma parada do velho novo?". Quanto aos temas transversais, as dissertações trataram sobre a educação ambiental, a violência escolar, o consumo sustentável, a saúde, os direitos humanos, como demonstra o título da dissertação de Silva (2012): "Juventude rural e as representações sobre a AIDS". E, por fim, 05 dissertações e teses englobaram assuntos sobre o trabalho docente, subdivido em: a identidade docente, a qualidade de vida e as práticas pedagógicas, como ilustrado na dissertação de Colares (2015) que analisou os indicadores de qualidade de vida dos professores do Ensino Médio Integrado, pertencentes a Rede Federal, do estado de Santa Catarina.

Sobre os índices das temáticas por ano, encontrou-se disparidade com relação ao aparecimento nas produções acadêmicas, o resumo ilustrativo desse dado apresenta-se na Figura 14:

Figura 14: Distribuição das temáticas por ano.

\begin{tabular}{|l|l|l|l|l|l|l|c|c|c|}
\hline & & & \\
\hline
\end{tabular}

Fonte: os autores.

Com relação aos temas abordados, notam-se algumas tendências da produção de conhecimento sobre o Ensino Médio Integrado no Brasil, tais como: a recorrência das temáticas "concepções do Ensino Médio Integrado" e "construção, implementação e efetivação do Ensino Médio Integrado", desde 2009; o aparecimento recente das temáticas "trabalho docente", em 2014, e "políticas institucionais", em 2015; o crescimento do interesse pelas temáticas "experiências didático-pedagógicas", a partir de 2010; e a ênfase da "integração curricular", nos anos de 2013 e de 2015, do "perfil do aluno", no ano de 2017, das "políticas públicas", nos anos de 2014, 2017 e 2018, e dos "temas transversais", no ano de 2012.

De forma mais detalhada, sintetiza-se que, nesses 10 anos pós-criação dos IFs, as produções acadêmicas sobre Ensino Médio Integrado preocuparam-se em compreender as suas concepções e em descrever a sua implementação, uma vez que é uma política educacional recente, em termos da integração entre o Ensino Médio e a Educação Profissional. Corroborando com o estudo de Faveri, Petterini e Barbosa (2018), que demostrou a existência de literatura que trata dos aspectos normativos dessa política, 
porém sem a previsão e intenção do monitoramento de indicadores de impacto, durante a formulação e a implantação da política.

As produções também voltaram-se para as experiências didático-pedagógicas no Ensino Médio Integrado, centradas, sobretudo, nos anos 2013, 2015 e 2018. No entanto, essas experiências didáticos-pedagógicas ainda são, na sua maioria, disciplinares, com origem de um movimento individualizado dos professores de algumas áreas do conhecimento, especialmente, os das Linguagens, os da Ciência da Natureza e os da Matemática, correlacionadas, como por exemplo, as áreas do Programa Internacional de Avaliação de Estudantes (PISA), no qual a Rede Federal tem demonstrado um desempenho superior em comparação com o obtido pelo Brasil, o que para Araújo e Silva (2017) traduz as condições objetivas de trabalho e de financiamento oferecidas para o Ensino Médio Integrado dos IFs, isso permite transformá-lo em uma referência de educação de qualidade, o qual deveria ser expandido para os demais sistemas de ensino. "Portanto, não se trata de milagre! Trata-se, apenas, de enxergar o que a evidência aponta” (CARNEIRO, 2012, p. 161).

Por um lado, esse avanço expressivo na produção de conhecimento sobre as experiências didático-pedagógicas no Ensino Médio Integrado sinaliza a inquietação e o interesse dos pesquisadores/professores em propor alternativas para o ensino-aprendizagem, por meio de práticas pedagógicas inovadoras. Mas por outro lado, as produções não têm contemplado os pressupostos metodológicos da interdisciplinaridade, um dos princípios norteadores do currículo integrado, consequentemente, da formação integrada, vislumbrada pelo Ensino Médio Integrado dos IFs, como consta nos artigos VII e VIII da Resolução no 6/2012, que define as Diretrizes Curriculares Nacionais para a Educação Profissional Técnica de Nível Médio.

Tal contexto não é exclusivo dos IFs, Spelt et al. (2009), após realizar uma revisão sistemática, apontou que os estudos sobre o ensino e a aprendizagem interdisciplinar no ensino superior ainda se encontravam limitados, restritos ao nível exploratório. Isto é, concentravam-se nos aspectos teóricos da interdisciplinaridade, deixando de lado a investigação sobre os modelos e as experiências de como trabalhar o ensino e a aprendizagem de modo interdisciplinar. Mozena e Ostermann (2014) também apontam para a carência de pesquisas que explorem acerca de concepções e ações interdisciplinares. Fato explicado pela literatura, a qual tem elencado como problemas para o desenvolvimento da interdisciplinaridade no ensino: às condições de trabalho e a falta de formação do professor (SHAW; ROCHA; FOLMER, 2017).

Por isso, Fazenda (2012) defende que o trabalho interdisciplinar depende de vontade, de condições adequadas e de saberes, além de uma atitude interdisciplinar para favorecer a inter-relação de conhecimentos, metodologias e aspectos epistêmicos de diferentes áreas. No entanto, apesar das condições favoráveis a isso nos IFs, nesse ínterim de 10 anos, não se destacaram as produções acadêmicas sobre a integração curricular no Ensino Médio Integrado, o que faz correspondência aos poucos estudos referentes ao currículo integrado e à prática interdisciplinar, em virtude, dos inúmeros desafios para superar a disciplinarização. Nesse sentido, Ciavatta (2016) compreende que o currículo integrado ainda está em curso, em construção perene trazendo consigo empolgação, mas também incertezas e insucessos.

Tal fenômeno aponta para a necessidade de estudos que investiguem sobre o planejamento, a implementação e a avaliação de práticas integradoras, ou seja, que objetivem descrever, compreender e analisar como se dá a integração curricular na práxis do Ensino Médio Integrado, sobretudo, por meio de pesquisas aplicadas. Uma vez que as produções acadêmicas sobre a integração curricular tratam de experiências pontuais de alguns IFs, como é o caso da Prática Profissional Integrada, desenvolvida pelo Instituto Federal Farroupilha. Apesar desse aparecimento, Minuzzi, Baccin e Coutinho (2019, p. 268) têm percebido "pouco compartilhamento dessas práticas integradoras realizadas no Ensino Médio Integrado, em âmbito nacional, e sobretudo, no contexto da PPI, a qual assume o trabalho e a pesquisa como princípios educativos, assim como a interdisciplinaridade e a contextualização", com as dimensões da ciência, da tecnologia, do trabalho e da cultura.

Nota-se também o crescente interesse por estudos referentes ao perfil dos alunos dos IFS, a partir de 2013, cujo tema se justifica primeiro pela importância de se conhecer a identidade das instituições para construir a política, e depois pela intencionalidade e pelo direcionamento dessas políticas institucionais, sinalizadas como tema no ano de 2015, relacionam ao debate em torno da inclusão dos 
IFs, a partir de 2010, no Programa Nacional de Assistência Estudantil (PNAES) e o incremento orçamentário, via Lei Orçamentária Anual (LOA), da ação intitulada "2994 - Assistência ao Educando da Educação Profissional”. Isso induziu os IFs a elaborarem suas políticas de assistência estudantil, baseadas em suas especificidades, com a oferta de ações voltadas para saúde, cultura, esporte e inclusão digital, devendo ir além do atendimento socioassistencial.

Porém, Taufick (2014, p. 199) pontua que, apesar de o PNAES alavancar a discussão sobre a política assistencial nos IFs, houve um descompasso financeiro e operacional, em virtude do perfil dos alunos das universidades federais, para os quais o programa foi, inicialmente, pensado. "Surge, desta forma, a constatação de que a política de assistência estudantil dos institutos federais precisa de outro marco legal, que garanta a consolidação e a ampliação dos benefícios entre os estudantes destas instituições".

E, por fim, os estudos que versam sobre políticas públicas, trabalho docente e temas transversais apresentaram uma baixa representatividade e periodicidade em comparação com as pesquisas sobre as temáticas "concepções do Ensino Médio Integrado", "construção, implementação e efetivação do Ensino Médio Integrado" e "as experiências didático-pedagógicas no Ensino Médio Integrado", as quais representam as tendências da produção de conhecimento sobre Ensino Médio Integrado.

Quanto aos participantes das pesquisas, identificou-se que a maioria $(40,8 \%)$ elegeu os alunos como sujeitos, seguido pelos professores, que apareceram em 17,6\% (28) produções acadêmicas como população a ser estudada. E, sobre o cenário (lócus) das dissertações e teses, destacam-se os IFs localizados na região Nordeste, em espacial, o Instituto Federal da Bahia. Isso condiz com a maior produção acadêmica, notadamente, as dissertações serem oriundas do Nordeste, e com o fato de a Universidade Federal da Bahia ter o maior número de trabalhos publicados pelos Programas de Pósgraduação, se comparada com outras Instituições de Ensino Superior. Esses dados podem ser visualizados na Figura 15.

Figura 15: Lócus das produções acadêmicas.

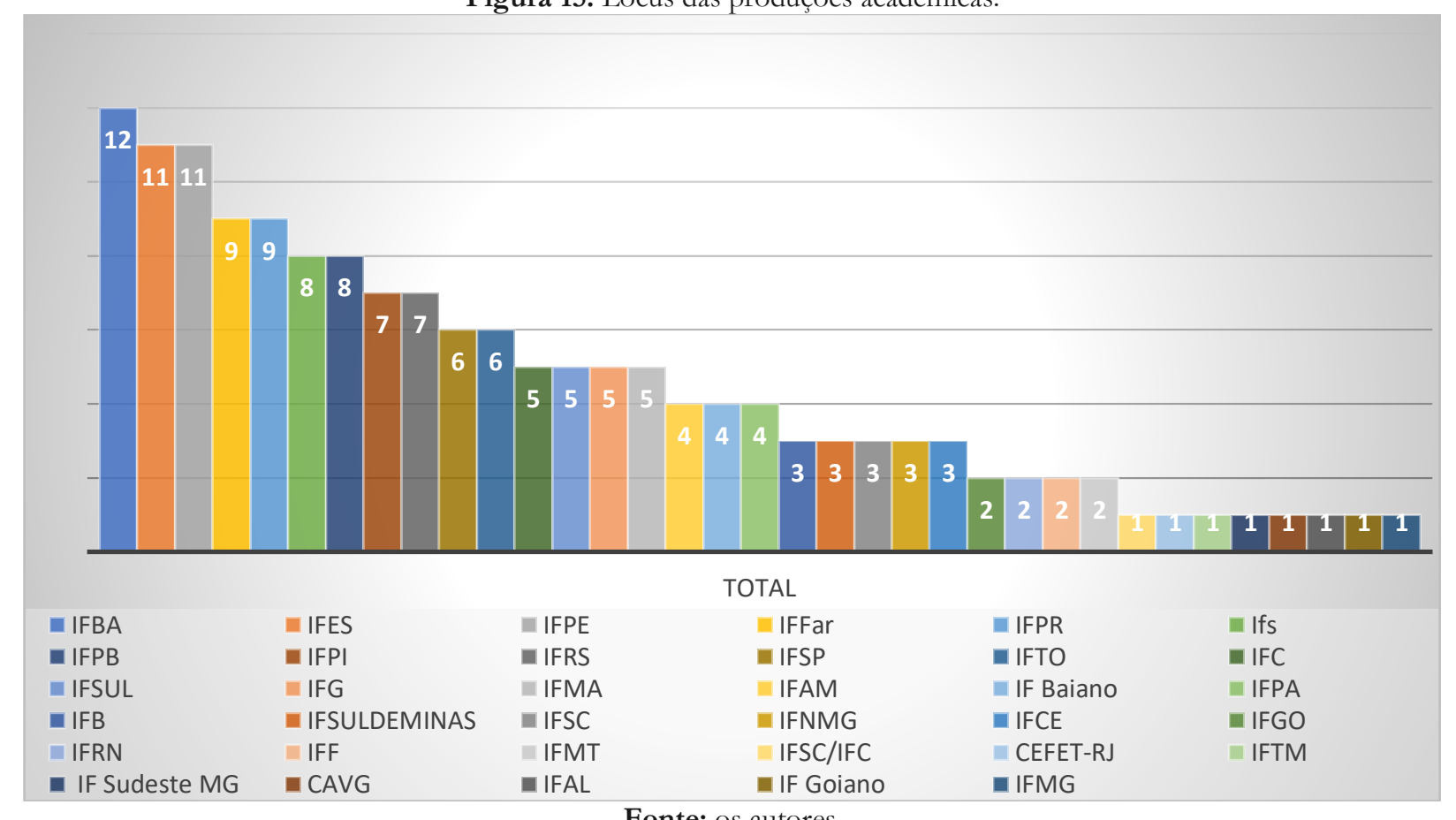

Fonte: os autores.

\section{CONSIDERAÇÕES FINAIS}

Com base na análise cienciométrica apresentada neste estudo, pode-se salientar que houve um aumento significativo das produções acadêmicas acerca do Ensino Médio Integrado as quais 
passaram, por exemplo, de 03 dissertações publicadas em 2009 para 24 em 2015, e de 02 teses publicadas em 2012 para 09 em 2017, em virtude, da expansão da pós-graduação no país e da criação e ampliação dos Institutos Federais. Essas são oriundas, na sua maioria, dos Programas de Pós-graduação concentrados na área de Educação (84).

Destaca-se também, a contribuição dos mestrados profissionais e dos Programas de Pósgraduação da área de Ensino (21), os quais incentivam a produção de conhecimento voltada às demandas e aos desafios da educação básica e buscam qualificar os professores, consequente, melhorar o processo de ensino-aprendizagem do Ensino Médio Integrado. Além disso, a região Nordeste abrangeu 42 das 128 dissertações, e as regiões Sudeste e Sul centralizaram 20 das 31 teses. Também foi possível identificar que grande parte das dissertações e teses sobre Ensino Médio Integrado, quanto à natureza, caracterizamse como pesquisa básica, uma vez que 100 estudos geraram novos conhecimentos, sem apontar potenciais soluções. Diferentemente, as outras 59 produções acadêmicas buscaram aplicar ações concretas ou propor soluções a problemas específicos, embora alguns dos resultados exigidos pelos mestrados profissionais referem-se à construção de um produto educacional além da dissertação.

Em relação à forma de abordagem do problema, constatou-se que 105 dissertações e teses referenciam a pesquisa qualitativa, uma vez que buscam entender o Ensino Médio Integrado como fenômeno social, diante da sua totalidade, historicidade e complexidade, por meio da utilização de narrativas e transcrições literais de verbalização dos sujeitos, tanto dos professores quanto dos alunos e também há a predominância para o tipo estudo de caso (35) e a pesquisa-ação (15).

Quanto aos procedimentos técnicos, 75 produções acadêmicas utilizaram-se de múltiplos registros (documentos oficiais e institucionais, entrevistas, questionário, diário de campo, fotos, filmagens, entre outros) como instrumentos de coleta de dados, para firmar o rigor cientifico da abordagem qualitativa, caracterizando-se como pesquisas empíricas, e 26 estudos escolheram a análise de conteúdo de Bardin para interpretar os dados.

E, por último, ao considerar a temática, verificou-se que a maioria dos estudos agrupam-se sob as "experiências didático-pedagógicas" (51), as "concepções sobre o Ensino Médio Integrado" (34) e a "construção, implementação e efetivação do Ensino Médio Integrado" (18). Essas temáticas são recorrentes e firmam-se como tendência, desde 2010, junto com o aparecimento recente do interesse de investigação voltado ao "perfil do aluno" e as "políticas institucionais". Logo, os resultados encontrados demonstraram que a produção do conhecimento sobre Ensino Médio Integrado, relevado pela Biblioteca Digital Brasileira de Teses e Dissertações, entre janeiro de 2008 a março de 2019, centra-se na pesquisa básica, com abordagem qualitativa e a temática recorre, principalmente, para as experiências didáticopedagógicas, sobretudo, as disciplinares, advindas da região Nordeste e de Programas de Pós-graduação de Educação.

Porém, a síntese cienciométrica dos estudos nos sugere que temos muito a avançar no número de teses de natureza aplicada e estratégica e de abordagem qualitativa, sucedidas das regiões Norte e Nordeste e com interesse nas temáticas de integração curricular, de práticas interdisciplinares e políticas públicas, contemplados por Programas de Pós-graduação na área do Ensino e Interdisciplinar. Além de reforçar as dissertações oriundas dos mestrados profissionais, de natureza estratégica, com abordagem quali-quantitativa, advindas das regiões Norte, Centro-Oeste e Sudeste, como é o caso da Universidade de São Paulo, e que abordem as experiências didático-pedagógicas, sob a perspectiva da interdisciplinaridade, e a materialização da integração curricular.

Tais resultados indicam a necessidade de se pensar em pesquisas aplicadas que estabeleçam o diálogo entre as áreas do conhecimento. Podendo ser ampliadas, por exemplo, pelo fortalecimento de estudos voltados a efetivação da integração curricular, contextualização, interdisciplinaridade, consequentemente, da formação integral, dada através do currículo integrado e das práticas integradas, os quais totalizam apenas 14 das 159 produções acadêmicas analisadas. E, em produções acadêmicas que avaliem os impactos e a eficiência da qualidade do Ensino Médio Integrado, de forma quantitativa, perante os índices nacionais e internacionais, já que não encontramos nenhum estudo avaliativo da sua implementação, enquanto política educacional.

Dessa forma, quanto mais a produção de conhecimento acerca do Ensino Médio Integrado, ofertado pelos IFs, estiver quantificada e avaliada, mais se caminha em direção à sua legitimação, 
efetivação e ampliação como uma travessia para a omnilateridade, politecnia e formação humana integral. Isso deve ocorrer, por meio de políticas educacionais, conhecimentos científicos e práticas pedagógicas integradoras bem definidas que possibilitam o aprofundamento coletivo dos seus desafios e da sua continuidade frente ao momento de retrocessos advindos dos cortes orçamentários e da atual reforma do Ensino Médio. Logo, o fortalecimento do Ensino Médio Integrado, enquanto área de conhecimento e prática, significa um movimento de resistência e luta coletiva e propositiva pela educação básica pública, gratuita e de qualidade.

\section{REFERÊNCIAS}

ABRANTES, A. A.; MARTINS, L. M. A produção do conhecimento científico: relação sujeito-objeto e desenvolvimento do pensamento. Interface - Comunic., Saúde, Educ., Botucatu, v. 11, n. 22, p. 31325, mai./ago. 2007.

ANDRÉ, M. Pesquisa em educação: questões de teoria e método. Revista Educação e Tecnologia, Belo Horizonte, v. 10, n. 1, p. 29-35, jan./jun. 2005.

ANDRÉ, M. O que é um estudo de caso qualitativo em educação? Revista da FAEEBA: Educação e Contemporaneidade, Salvador, v. 22, n. 40, p. 95-103, jul./dez. 2013.

ARAÚJO, A. C.; SILVA, C. N. N. Ensino médio integrado no Brasil: fundamentos, práticas e desafios. Brasília: Ed. IFB, 2017.

BALDISSERA, A. Pesquisa-ação: uma metodologia do "conhecer" e do "agir" coletivo. Sociedade em Debate, Pelotas, v. 7, n. 2, p. 5-25, ago. 2001.

BARDIN, L. Análise de conteúdo. São Paulo: Edições 70, 2011.

BARRETO FILHO, E. M. Obesidade na adolescência: a interdisciplinaridade como estratégia de promoção da saúde. 2016. 133 f. Dissertação (Mestrado Profissional de Ensino na Saúde) - Escola de Enfermagem Aurora de Afonso Costa, Universidade Federal Fluminense, Niterói, 2016.

BARROS, M. M. Violência escolar entre alunos do ensino médio integrado: uma análise a partir do Instituto Federal do Ceará-Campus Iguatu. 2015. 98 f. Dissertação (Mestrado em Teologia) Programa de Pós-Graduação em Teologia, Escola Superior de Teologia, Rio Grande do Sul, 2015.

BENTES, H. V. Concepção e prática do ensino médio integrado: a percepção dos professores da ETF Palmas - Tocantins. 2009. 138 f. Dissertação (Mestrado em Educação) - Faculdade de Educação, Universidade de Brasília, Brasília, 2009.

BEZERRA, D. S. Políticas e planejamento do ensino médio (integrado ao técnico) e da língua estrangeira (inglês): na mira(gem) da politecnia e da integração. 2012. 203 f. Tese (Doutorado em Educação) - Faculdade de Educação, Universidade de São Paulo, São Paulo, 2012.

BOGDAN, R.; BIKLEN, S. Investigação qualitativa em educação: uma introdução à teoria e aos métodos. Porto: Porto Editora, 1994.

BORGES, E. C. Clio e titãs: as representações sobre o ensino de História no contexto da educação profissional do IFES. 2016. 200 f. Dissertação (Mestrado em Ensino na Educação Básica) Centro Universitário Norte do Espírito Santo, Universidade Federal do Espírito Santo, Espírito Santo, 2016. 
BOSCATTO, J. D. Proposta curricular para a Educação Física no Instituto Federal de Santa Catarina: uma construção colaborativa virtual. 2017. 164 f. Tese (Doutorado em Desenvolvimento Humano e Tecnologias) - Instituto de Biociências de Rio Claro, Universidade Estadual Paulista, São Paulo, 2017.

BRASIL, Presidência da República. Casa Civil. Subchefia para Assuntos Jurídicos. Decreto $\mathbf{n}^{\mathbf{0}}$ 5.154, de 23 de julho de 2004. Regulamenta o $\ 2^{\circ}$ do art. 36 e os arts. 39 a 41 da Lei ${ }^{\circ}$ 9.394, de 20 de dezembro de 1996, que estabelece as diretrizes e bases da educação nacional, e dá outras providências. Brasília: 2004. Disponível em: http://www.planalto.gov.br/ccivil_03/_ato2004-2006/2004/decreto/d5154.htm. Acesso em 27 de abr. 2019.

BRASIL, Presidência da República. Casa Civil. Subchefia para Assuntos Jurídicos. Lei $\mathbf{n}^{\mathbf{0}}$ 11.892, de 29 de dezembro de 2008. Institui a Rede Federal de Educação Profissional, Ciência e Tecnológica, cria os Institutos Federais de Educação, Ciência e Tecnologia. Brasília: 2008. Disponível em: http://www.planalto.gov.br/ccivil_03/_Ato2007-2010/2008/Lei/L11892.htm. Acesso em 27 de abr. 2019.

BRASIL, Ministério da Educação. Plataforma Nilo Peçanha. Rede Federal de Educação Profissional, Científica e Tecnológica SETEC/MEC Disponível em: http://resultados.plataformanilopecanha.org/2018/. Acesso em 25 de set. 2018.

BRESOLIN, E. Diálogos interdisciplinares na prática profissional integrada de um curso técnico de ensino médio. 2016. 164 f. Dissertação (Mestrado em Educação nas Ciências) - Universidade Regional do Noroeste do Estado do Rio Grande do Sul (Campus Ijuí e Santa Rosa), Rio Grande do Sul, 2016.

CARNEIRO, M. A. O nó do ensino médio. Rio de Janeiro: Vozes, 2012.

CASTRO, F. G.; KELLISON, J. G. BOYD, S. J.; KOPAK, A. A Methodology for conducting integrative mixed methods research and data analyses. Journal of Mixed Methods Research, v. 4, n. 4, p. 342-360, 2010.

CAVALCANTI, V. O. M.; NETA, O. M. M. A produção do conhecimento sobre educação profissional: o mapeamento dos artigos científicos no portal de periódicos da capes. RBEPT, Natal, v. 2, n. 9, p. 111, 2015.

CIAVATTA, M. A produção do conhecimento sobre s configuração do campo da Educação Profissional e Tecnológica. HOLOS, Natal, v. 6, p. 33-49, 2016.

COLARES, M. C. Indicadores de qualidade de vida de professores de ensino médio integrado da rede federal no Estado de Santa Catarina. 2015. 151 f. Dissertação (Mestrado em Educação Física) Centro de Desportos, Programa de Pós-Graduação em Educação Física, Universidade Federal de Santa Catarina, Florianópolis, 2015.

CORREIA, J. M. S. Os sentidos da política de assistência estudantil para estudantes do ensino médio integrado do Instituto Federal da Bahia (Campus Jacobina, 2014 - 2017). 2018. 138 f. Dissertação (Mestrado em Educação) - Faculdade de Educação, Universidade Federal da Bahia, Bahia, 2018.

COUTINHO, R. X.; SOARES, M. C.; FOLMER, V.; PUNTEL, R. L. Análise da produção de conhecimento da Educação Física brasileira sobre o cotidiano escolar. Revista Brasileira de PósGraduação, Brasília, v. 9, n. 17, p. 491-516, jul. 2012. 
CRESWELL, J. Projeto de pesquisa: métodos qualitativo, quantitativo e misto. Porto Alegre: Artmed, 2007.

DELLA VOPE, A. L. Pigmentos inorgânicos como tema para interdisciplinaridade e contextualização no ensino de química. 2018. 272 f. Dissertação (Mestrado Profissional em Química) - Centro de Ciências Exatas e de Tecnologia, Universidade Federal de São Carlos, São Paulo, 2018.

DEMO, P. Metodologia do conhecimento científico. São Paulo: Atlas, 2000.

DIAS, V. E. M. A educação integrada e a profissionalização no ensino médio. 2015. 239 f. Tese (Doutorado em Educação) - Centro de Educação e Ciências Humanas, Universidade Federal de São Carlos, São Paulo, 2015.

DRAGO, C. C. A formação humana no ensino médio integrado: o que dizem as pesquisas. Trabalho Necessário, Niterói, v. 15, n. 28, p. 90-107, 2017.

FAVERI, D. B.; PETTERINI, F. C.; BARBOSA, M. P. Uma avaliação do impacto da política de expansão dos Institutos Federais nas economias dos municípios brasileiros. Revista Planejamento e Políticas Pública, Brasília, n. 50, jan./jun. 2018.

FAZENDA, I. Integração e interdisciplinaridade no ensino brasileiro: efetividade ou ideologia. 6. ed. São Paulo: Loyola, 2011.

FAZENDA, I. Interdisciplinaridade: História, teoria e pesquisa. São Paulo: Papirus, 2012.

FEITOSA, J. F. Aspirações dos alunos do ensino médio Integrado do Instituto Federal do Piauí - campus Floriano: levantamento e análise. 2018. 146 f. Dissertação (Mestrado em Educação) Programa de Pós-Graduação em Educação, Universidade Nove de Julho, São Paulo, 2018.

FERNANDES, M. B. Eletricidade: uma sequência didática para o ensino médio integrado. 2015. 163 f. Dissertação (Mestrado Profissional em Ensino de Ciências) - Universidade Federal do Pampa, Campus Bagé, Rio Grande do Sul, 2015.

FERREIRA, L. S. A pesquisa educacional no Brasil: tendências e perspectivas. Contrapontos, Itajaí, v. 9, n. 1, p. 43-54, jan./abr. 2009.

FIGLIUOLO, A. C. L. Ensino Médio Integrado: um estudo de caso sobre a percepção docente acerca da implementação do Decreto $\mathrm{n}^{\circ}$ 5.154/04 no curso de turismo do Instituto Federal de Educação, Ciência e Tecnologia do Pará - Campus Belém. 2010. 96 f. Dissertação (Mestrado em Educação) - Faculdade de Educação, Universidade de Brasília, Brasília, 2010.

FREIRE, P. Pedagogia da autonomia: saberes necessários à prática educativa. São Paulo: Paz e Terra, 1996.

GARCIA, J. C. O ensino médio integrado no instituto federal goiano: a percepção de professores sobre os desafios e possibilidades para a consolidação da formação humana integral. 2017. 266 f. Tese (Doutorado Educação) - Pontifícia Universidade Católica de Goiás, Goiânia, 2017.

GATTI, B. A. A construção da pesquisa em educação no Brasil. Brasília: Plano Editora, 2002. 
GATTI, B. A. Estudos quantitativos em educação. Educação e Pesquisa, São Paulo, v. 30, n. 1, p. 1130, jan./abr. 2004.

GIANELLI, J. G. O INSTITUTO FEDERAL DE EDUCAÇÃO, CIÊNCIA E TECNOLOGIA DE SÃO PAULO - CAMPUS SÃO JOÃO DA BOA VISTA: a questão do Ensino Médio Integrado. 2018. 328 f. Tese (Doutorado em Educação) - Centro de Educação e Ciências Humanas, Universidade Federal de São Carlos, São Paulo, 2018.

GIL, A. C. Métodos e Técnicas da Pesquisa Social. 6. ed. São Paulo: Atlas, 2008.

GIL, A. C. Como elaborar projetos de pesquisa. 5. ed. São Paulo: Atlas, 2010.

GOERGEN, P. A pesquisa educacional no Brasil: dificuldades, avanços e perspectivas. Em aberto, Brasilia, v. 5, n. 31, jul./set. 1986.

GOLDENBERG, M. A arte de pesquisar: como fazer pesquisa em Ciências Sociais. 8. ed. Rio de Janeiro: Record, 2004.

GUEDES, F. L. Projeto de vida e a constituição do profissional técnico do IFSULSAP: expectativas de jovens diante de um Projeto de Educação Profissional Integrada. 2017. 348 f. Tese (Doutorado em Educação) - Universidade do Vale do Rio do Sinos, Rio Grande do Sul, 2017.

GUSMÃO, C. A. Educação profissional técnica de nível médio integrada ao ensino médio: a perda do caráter profissionalizante? 2016. 181 f. Dissertação (Mestrado Profissional em Educação) Faculdade de Educação, Universidade de Brasília, Brasília, 2016.

LIEVORE, C.; PICININ, C. T.; PILAT'TI, L. A. As áreas do conhecimento na pós-graduação stricto sensu brasileira: crescimento longitudinal entre 1995 e 2014. Ensaio: aval. pol. públ. Educ., Rio de Janeiro, v. 25, n. 94, p. 207-237, Jan./Mar. 2017.

MACIAS-CHAPULA, C. A. O papel da informetria e da cienciometria e sua perspectiva nacional e internacional. Ciência da Informação, Brasília, v. 27, n. 2, p. 134-140, maio/ago. 1998.

MARÇAL, F. A. O ensino médio integrado no IFRS enfrentando a dualidade. 2015. 212 f. Tese (Doutorado em Educação) - Faculdade de Educação, Universidade Federal do Rio Grande do Sul, Rio Grande do Sul, 2015.

MATOS, É. F. R. Histórias planejadas? Uma análise sobre “juventudes”, escola e projetos de futuro no ensino médio integrado do IFS em Aracaju. 2017. 131 f. Dissertação (Mestrado em Educação) - Programa de Pós-Graduação em Educação, Universidade Federal de Sergipe, São Cristóvão, 2017.

MÉSZÁROS, I. A Educação para além do Capital. 2. ed. São Paulo: Boitempo, 2008.

MINAYO, M. C. S. Pesquisa Social: Teoria, método e criatividade. 29. ed. Petrópolis: Vozes, 2010.

MINUZZI, E. D.; BACCIN, B. A.; COUTINHO, R. X. Prática profissional integrada (PPI) - dos princípios à ação no Ensino Médio Integrado. Revista de Estudos e Pesquisas sobre Ensino Tecnológico (EDUCITEC), Manaus, v.5, n. 12, p. 250-273, 2019.

MOREIRA, M. A. Metodologias de Pesquisa em Ensino. São Paulo: Livraria da Física, 2011. 
MOZENA, E. R.; OSTERMANN, F. Uma revisão bibliográfica sobre a interdisciplinaridade no ensino das ciências da natureza. Revista Ensaio, Belo Horizonte, v. 16, n. 02, p. 185-206, maio./ago. 2014.

PINTO, J. C. A. Desempenho acadêmico e fatores socioeconômicos: uma análise no ensino médio integrado do IFBA/Campus Barreiras. 2015. 112 f. Dissertação (Mestrado em Educação) Faculdade de Educação, Universidade Federal da Bahia, Bahia, 2015.

PONTES JÚNIOR, J. A. F. Avaliação do ensino-aprendizagem nas aulas de educação física nas escolas públicas e particulares de Fortaleza-CE. 2012. 85f. Dissertação (Mestrado em Educação) Faculdade de Educação, Universidade Federal do Ceará, Ceará, 2012.

RAZERA, J. C. C. Contribuições da cienciometria para a área brasileira de Educação em Ciências. Ciência e Educação, Bauru, v. 22, n. 3, p. 557-560, 2016.

ROSA, S. Relação entre educação e trabalho no curso técnico em agropecuária integrado ao ensino médio. 2015. 2018 f. Dissertação (Mestrado em Educação) - Pontifícia Universidade Católica de Goiás, Goiânia, 2015.

SAVIANI, D. Escola e democracia. São Paulo: Cortez, 1984.

SHAW, G. S. L.; ROCHA, S. J. B. T.; FOLMER, V. Uma revisão sobre a interdisciplinaridade no ensino e a formação de professores. Revista Ciências e Ideias, Nilópolis, v. 8, n.1, p. 202-226, jan./abr. 2017.

SCHÖN, D. Formar professores como profissionais reflexivos. In: NÓVOA, A. (Org.). Os professores e a sua formação. Lisboa: Publicações Dom Quixote, 1992. p. 79-92.

SILVA, C. E. C. Assistência estudantil e ensino médio integrado: um estudo sobre as relações entre o Programa de Incentivo ao Esporte e Lazer e a permanência escolar. 2017. 215 f. Dissertação (Mestrado em Educação) - Universidae Federal de Pernambuco, Recife, 2017.

SILVA, E. L.; MENEZES, E. M. Metodologia de pesquisa e elaboração de dissertação. 3. ed. Florianópolis: Editora da UFSC, 2001.

SILVA, G. A. A formação humana integral e o ensino médio (integrado) no contexto das reformas educacionais (2016-2017): uma parada do velho novo? 2017. 102 f. Dissertação (Mestrado em Sociologia) - Universidade Federal de Goiás, Goiânia, 2017.

SILVA, M. A. C. R. Diversidade cultural na diversidade alimentar: comida na Tríplice Fronteira. 2018. 101 f. Dissertação (Mestrado em Ensino das Ciências Ambientais) - Centro de Ciências do Ambiente, Universidade Federal do Amazonas, Amazonas, 2018.

SILVA, M. M. C. Juventude rural e as representações sobre a AIDS. 2012. 207 f. Dissertação (Mestrado em Extensão Rural) - Universidade Federal de Viçosa, Minas Gerais, 2012.

SILVA FILHO, G. C. Formação, projetos profissionais e projetos de vida: olhares dos estudantes do curso de técnico em administração integrado ao ensino médio do IFPI - Campus de São Raimundo Nonato. 2018. 240 f. Dissertação (Mestrado em Educação) - Universidade Nove de Julho UNINOVE, São Paulo, 2018.

SMANIOTTO, D. M. Autonomia, autoridade e formação moral em Kant e Piaget. 2015. 59 f. Dissertação (Mestrado em Educação) - Faculdade de Educação, Universidade de Passo Fundo, Rio Grande do Sul, 2015. 
SOARES, L. V. A construção de experimentos pelos alunos do ensino técnico integrado ao médio: uma proposta de resolução de problemas no contexto de uma mostra escolar de ciência e tecnologia. 2015. 115 f. Dissertação (Mestrado em Ensino de Física) - Centro de Ciências Exatas, Universidade Federal do Espírito Santo, Espírito Santo, 2015.

SPELT, E. J. H.; BIEMANS, H. J. A.; TOBI, H.; LUNING, P. A.; MULDER, M. Teaching and Learning in Interdisciplinary Higher Education: A Systematic Review. Educ. Psychol. Rev., v. 21, p. 365-378, 2009.

SPINAK, E. Dicionário enciclopédico de bibliometria, cienciometria e informetria. Caracas: UNESCO, 1996.

STRAUSS, A.; CORBIN, J. Pesquisa qualitativa - técnicas e procedimentos para o desenvolvimento de teoria fundamentada. Porto Alegre: Artmed, 2008.

TAUFICK, A. L. O. L. Análise da Política de Assistência Estudantil dos Institutos Federais de Educação, Ciência e Tecnologia. RBPAE, Porto Alegre, v. 30, n. 1, p. 181-201, jan./abr. 2014.

THESING, M. L. C.; COSTAS, F. A. T. A pesquisa em educação: aproximações iniciais. Revista IberoAmericana de Estudos em Educação, Araraquara, v. 12, n. 3, p. 1839-1853, jul./set. 2017.

THIOLLENT, M. Metodologia da Pesquisa-Ação. São Paulo: Cortez,1985.

VANTI, N. A. P. Da bibliometria à webometria: uma exploração conceitual dos mecanismos utilizados para medir o registro da informação e a difusão do conhecimento. Ciência da Informação, Brasília, v. 31, n. 2, p. 152-162, mai./ago. 2002.

VEIGA, C. R. Fatores predominantes da evasão escolar no ensino médio integrado: uma proposta de estratégia de prevenção para o CEFET/RJ. 2016. 102 f. Dissertação (Mestrado em Sistema de Gestão) - Escola de Engenharia, Universidade Federal Fluminense, São Paulo, 2016.

VIEIRA, J. A.; VIEIRA, M. M. M. Formação integrada do ensino médio com a educação profissional: o que dizem as pesquisas. Revista Thema, v. 13, n. 1, p. 79-92, 2016.

VIROTE, S. M. P. A Educação Profissional Técnica de Nível Médio Integrada ao Ensino Médio: implicações das mudanças legais no Governo Lula para o IFG. 2009. 188 f. Dissertação (Mestrado em Ciências Humanas) - Pontifícia Universidade Católica de Goiás, Goiânia, 2009.

XIMENES NETO, J. C. O ensino de geografia na educação patrimonial: ações educativas no ensino médio integrado do IFPB de Catolé do Rocha - PB. 2017. 191 f. Dissertação (Mestrado em Formação de Professores) - Universidade Estadual da Paraíba, Paraíba, 2017.

ZANCAN, S.; BOLZAN, D. P. V. Contextos emergentes na UFSM: a expansão da pós-graduação. Educação Por Escrito, Porto Alegre, v. 8, n. 2, p. 244-259, jul./dez. 2017.

ZIBENBERG, I. G. S. Permanência e êxito na passagem pelo ensino médio integrado: implicações do capital cultural e do ofício de aluno na seletividade escolar. 2016. 114 f. Dissertação (Mestrado em Educação) - Faculdade de Educação, Universidade Federal do Rio Grande do Sul, Rio Grande do Sul, 2016. 
ZUKOWSKI, N. B. S. Estudo comparativo entre o ensino médio integrado e o técnico subsequente no IFTO-câmpus Palmas: formação, empregabilidade, satisfação. 2013. 169 f. Dissertação (Mestrado Profissional em Educação) - Faculdade de Educação, Programa de PósGraduação em Políticas Públicas e Gestão da Educação Profissional e Tecnológica, Universidade de Brasília, Brasília, 2013.

Submetido: $13 / 09 / 2019$

Aprovado: 09/12/2019 